\title{
Group Contribution Methods for the Prediction of Thermophysical and Transport Properties of Ionic Liquids
}

\author{
Ramesh L. Gardas and João A. P. Coutinho \\ CICECO, Departamento de Química, Universidade de Aveiro, Aveiro 3810-193, Portugal
}

DOI 10.1002/aic.11737

Published online April 7, 2009 in Wiley InterScience (www.interscience.wiley.com).

\begin{abstract}
Thermophysical and transport properties of ionic liquids are required for the design of processes and products. Yet the experimental data available are scarce and often contradictory. Based on experimental data collected from the literature, group contribution methods were developed for the estimation of viscosity, electrical conductivity, thermal conductivity, refractive index, isobaric expansivity, and isothermal compressibility, of various families of ionic liquids. Using the Stokes-Einstein relation a correlation for the self-diffusion coefficients with the viscosity is also proposed. The results of the proposed models show average absolute relative deviations generally of the same order of the experimental accuracy of the data. They are easy to use and can provide predictions of property values for ionic liquids never previously studied. The group contribution basis of these models will allow them to be extended to new groups of cations and anions as further data became available. () 2009 American Institute of Chemical Engineers AIChE J, 55: 1274-1290, 2009
\end{abstract}

Keywords: ionic liquid, group contribution method, viscosity, conductivity, compressibility

\section{Introduction}

Ionic liquids (ILs) are novel solvents belonging to the class of molten salts liquid at room temperature that are expected to produce important developments in the industrial chemistry and chemical technology, and are spurring several research fields. They are, usually, the combination of large organic cations with various alkyl substituents and inorganic or organic anions; so the feasible number of ILs (from chemical combinations) is estimated to be more than a trillion. One of the major goals of the chemical industry today is to search for safer alternatives of volatile organic compounds (VOCs) that will minimize air pollution, climatic changes, and human health-related problems. ILs exhibit cer-

Correspondence concerning this article should be addressed to R. L. Gardas at this current address: The QUILL Research Centre, School of Chemistry and Chemical Engineering, Queen's University of Belfast, BT9 5AG, Northern Ireland, United Kingdom; r.gardas@qub.ac.uk or J. A.P.Coutinho at jcoutinho@ua.pt.

(C) 2009 American Institute of Chemical Engineers tain desirable physical properties, such as negligible vapor pressure, wide liquidus range, wide electrochemical window, wide thermal window, nonflammability, large range of densities, and viscosities, high potential for recycling, and highly solvating capacity for organic, inorganic and organometallic compounds, which merit the consideration of ILs to the replacement of VOCs in current processes or in the design of new processes and products based on the unique properties of these compounds. An interesting feature of ILs is that simple changes in the cation and anion combinations or the nature of the moieties attached to each ion allow the physical properties to be tailored for specific applications.

Although most effort in ILs has been focused on the investigation of their potential applications, the characterization of ILs properties and structure-property relationships of ILs is of equivalent importance but has lagged behind. The thermophysical and transport properties of ionic liquids are required for the design of processes and products involving these compounds. Yet the experimental data available is 
currently scarce for most properties and often data from various sources are contradictory.

Given the huge number of potential ILs, the experimental measurement of the thermophysical and transport properties for all ionic liquids of interest is unfeasible. The alternative is to develop predictive models, based on some experimental data, from which the required properties with the desired accuracy could be obtained. The development of group contribution methods for the properties of ionic liquids is particularly apt for this purpose as from a restricted amount of data it will help to expand the information available for a large number of compounds and will also allow for a critical evaluation of the accuracy of available data.

The possibility of tailoring the properties of an ionic liquid to meet the requirements of some specific application makes ILs designer solvents per excellence. Given the large number of potential ionic liquids, designing an ionic liquid by experimental trial an error or based on some empirical heuristics is not the most promising approach. ${ }^{1}$ The design of ionic liquids will certainly require the development of methods for Computer Aided Molecular Design (CAMD) of these compounds. Besides their obvious interest for the prediction of thermophysical and transport properties, group contribution methods are also at the basis of the development of CAMD methods. ${ }^{2,3}$

In this work, we intend to present group contribution methods that are employed to estimate thermophysical and transport properties of ILs. Our goal is to show that group contribution methods may be applied for rapid and facile prediction of physical properties with acceptable deviations for a wide range of ILs.

In a previous series of articles a number of predictive methods for density, ${ }^{4}$ surface tension, ${ }^{5}$ viscosity, ${ }^{6}$ speed of sound, ${ }^{7}$ and liquid heat capacity ${ }^{8}$ of ILs have been proposed. The development of group contribution methods for the transport and thermophysical properties of ionic liquids will be here completed with the presentation of new group contribution methods for the prediction of viscosity, electrical conductivity, thermal conductivity, refractive index, isobaric expansivity, and isothermal compressibility of ionic liquids. Moreover, a correlation for the self-diffusion coefficients of ionic liquids based on the Stokes-Einstein relation will also be proposed. It will be shown that the proposed models allow a good description of the respective experimental data available, usually within the agreement of experimental data by different authors as described on the report of the IUPAC task group for the development of standard systems for the measurement of thermodynamic properties of ionic liquids (http://www.iupac.org/web/ ins/2002-005-1-100). A brief discussion on the effect of the cation, anion and alkyl chain lengths on the property values will be done for each property investigated.

\section{Collection of physical properties of ILs}

The experimental viscosity, electrical conductivity, selfdiffusion coefficients, thermal conductivity, refractive index, isobaric expansivity, and isothermal compressibility data of the ILs, here used to estimate the group contribution parameters for the various correlations proposed, were taken from open literature concerning the physical properties of ILs, ${ }^{9-111}$ and from the International Union of Pure and
Applied Chemistry (IUPAC) database. ${ }^{112}$ The following IL ions were considered in this study: cations imidazolium [Im], pyridinium [Py], pyrrolidinium [Pyr], piperidinium [Pip], alkyl phosphonium $[\mathrm{Ph}]$, and alkyl ammonium [Am]; anions, hexafluorophosphate $\left[\mathrm{PF}_{6}\right]$, tetrafluoroborate $\left[\mathrm{BF}_{4}\right]$, bis(trifluoromethanesulfonyl) amide $\left[\mathrm{Tf}_{2} \mathrm{~N}\right]$, chloride $[\mathrm{Cl}]$, acetate $\left[\mathrm{CH}_{3} \mathrm{COO}\right]$, methyl sulfate $\left[\mathrm{MeSO}_{4}\right]$, ethyl sulfate $\left[\mathrm{EtSO}_{4}\right]$, trifluoromethanesulfonate $\left[\mathrm{CF}_{3} \mathrm{SO}_{3}\right]$, bis(perfluoroethylsulfonyl)imide $\left[\mathrm{Pf}_{2} \mathrm{~N}\right]$, trifluoroacetate $\left[\mathrm{CF}_{3} \mathrm{COO}\right]$, dimethylphosphate $\left[\left(\mathrm{CH}_{3}\right)_{2} \mathrm{PO}_{4}\right]$, methoxyethylsulfate $\left[\mathrm{CH}_{3} \mathrm{OC}_{2} \mathrm{H}_{4} \mathrm{SO}_{4}\right]$, dicyanamide $\left[\mathrm{N}(\mathrm{CN})_{2}\right]$, tricyanomethanide $\left[\mathrm{C}(\mathrm{CN})_{3}\right]$, tetrachloroalluminate $\left[\mathrm{AlCl}_{4}\right]$, tetrachloroironate $\left[\mathrm{FeCl}_{4}\right]$, tetrachlorogallate $\left[\mathrm{GaCl}_{4}\right]$, tetrachloroindate $\left[\mathrm{InCl}_{4}\right]$, and trichlorozincate $\left[\mathrm{ZnCl}_{3}\right]$. The combinations of cations and anions and the data points of the individual properties of the ILs studied in this work are presented in tables in next section.

\section{Results and Discussion}

\section{Viscosity}

The viscosities of ILs are relatively high compared to those of common organic solvents. Experimental viscosity data of ILs are still in short supply and restricted to a few families of well-studied ILs. More data and a better understanding of the viscosity of ILs are required for task-specific development. In the absence of experimental data, theoretical or empirical methods must be used to obtain acceptable estimation of viscosities as defined by the design specifications.

In a previous work, ${ }^{6}$ the viscosity of ILs was correlated using an Orrick-Erbar-type approach ${ }^{113}$ by estimating parameters $A$ and $B$ in Eq. 1:

$$
\ln \frac{\eta}{\rho \cdot M}=A+\frac{B}{T}
$$

where $\eta$ and $\rho$ are the viscosity in $\mathrm{cP}$ units and density in $\mathrm{g} \mathrm{cm}^{-3}$ units respectively. $M$ is the molecular weight and $T$ is the absolute temperature. Eq. 1 was used for circa 500 data points of 29 ILs providing a relative average deviation of $8 \%$ and a maximum deviation of $28 \%$. The Orrick-Erbar method requires density data for the prediction of viscosity. To overcome this limitation and to attempt the development of an improved viscosity model with lower deviations in estimated viscosities, a new correlation based on the Vogel-TammannFulcher (VTF) equation (Eq. 2) is here proposed. The data base of experimental viscosities of ILs used is reported in Table 1.

$$
\ln \eta=A_{\eta}+\frac{B_{\eta}}{\left(T-T_{0 \eta}\right)}
$$

where $\eta$ is viscosity in Pa s units, $T$ is temperature in $\mathrm{K}$, and $A_{\eta}, B_{\eta}$, and $T_{0 \eta}$ are adjustable parameters. The ratio of parameters $B_{\eta}$ and $T_{0 \eta}, B_{\eta} / T_{0 \eta}$, is also known as Angell strength parameter. As it will be shown below, $T_{0 \eta}$ is similar for all the ILs studied. $A_{\eta}$ and $B_{\eta}$, can be obtain by a group contribution method according to

$$
A_{\eta}=\sum_{i=1}^{k} n_{i} a_{i, \eta} \quad B_{\eta}=\sum_{i=1}^{k} n_{i} b_{i, \eta}
$$

where $n_{i}$ is the number of groups of type $i$ and $k$ is the total number of different groups in the molecule, and the parameters 
Table 1. Prediction of Viscosity of Imidazolium-, Pyridinium-, and Pyrrolidinium-Based Ionic Liquids

\begin{tabular}{|c|c|c|c|c|c|}
\hline Ionic Liquid & $\begin{array}{l}\text { Temperature } \\
\text { Range (K) }\end{array}$ & $\begin{array}{l}\text { Data } \\
\text { Points }\end{array}$ & $\begin{array}{l}\text { Relative Deviation } \\
\text { (range) }(\%)\end{array}$ & $\begin{array}{c}\text { Average Absolute } \\
\text { Relative Deviation (\%) }\end{array}$ & Reference \\
\hline \multirow[t]{4}{*}[\mathrm{C}_{4}\mathrm{mIm}]{$\left[\mathrm{PF}_{6}\right]$} & $293.15-353.15$ & 16 & $-3.49 ; 2.56$ & 1.57 & 19 \\
\hline & $293.15-353.15$ & 4 & $-4.21 ; 0.01$ & 2.05 & 29 \\
\hline & 293.1-353.1 & 8 & $3.70 ; 12.90$ & 10.59 & 28 \\
\hline & $293.15-323.15$ & 7 & $7.47 ; 9.58$ & 8.76 & 36 \\
\hline \multirow{3}{*}[\mathrm{C}_{6}\mathrm{mIm}]{$\left[\mathrm{PF}_{6}\right]$} & $293.15-323.15$ & 7 & $-11.90 ;-2.76$ & 7.29 & 36 \\
\hline & $293.15-353.15$ & 11 & $-15.43 ;-1.83$ & 7.84 & 33 \\
\hline & $293.15-303.15$ & 2 & $-14.17 ;-12.31$ & 13.24 & 11 \\
\hline \multirow{6}{*}[\mathrm{C}_{8}\mathrm{mIm}]{$\left[\mathrm{PF}_{6}\right]$} & 298.1 & 1 & -0.32 & 0.32 & 12 \\
\hline & $293.15-323.15$ & 7 & $-2.73 ; 4.32$ & 2.00 & 36 \\
\hline & $293.15-343.15$ & 11 & $-8.75 ; 2.92$ & 4.58 & 25 \\
\hline & $293.15-353.15$ & 4 & $-7.63 ; 7.60$ & 5.31 & 39 \\
\hline & $293.15-303.15$ & 2 & $7.25 ; 12.21$ & 9.73 & 11 \\
\hline & $293.15-303.15$ & 2 & $13.34 ; 14.01$ & 13.68 & 14 \\
\hline \multirow{8}{*}[\mathrm{C}_{4}\mathrm{mIm}]{$\left[\mathrm{BF}_{4}\right]$} & 298.1 & 1 & 4.26 & 4.26 & 41 \\
\hline & $293.15-353.15$ & 31 & $-3.45 ; 1.50$ & 1.58 & 34 \\
\hline & $293.15-323.15$ & 7 & $0.63 ; 1.34$ & 1.00 & 38 \\
\hline & $293.15-323.15$ & 6 & $-14.34 ; 22.77$ & 10.57 & 16 \\
\hline & $293.67-388.04$ & 11 & $-0.64 ; 22.31$ & 5.91 & 26 \\
\hline & $293.15-353.15$ & 4 & $3.08 ; 5.02$ & 4.26 & 29 \\
\hline & 293.1-353.1 & 8 & $1.24 ; 10.05$ & 5.98 & 28 \\
\hline & $293.1-303.1$ & 2 & $-10.46 ;-10.42$ & 10.44 & 11 \\
\hline$\left[\mathrm{C}_{6} \mathrm{mIm}\right]\left[\mathrm{BF}_{4}\right]$ & $293.15-323.15$ & 7 & $-5.94 ;-3.74$ & 4.57 & 38 \\
\hline \multirow{2}{*}[\mathrm{C}_{8}\mathrm{mIm}]{$\left[\mathrm{BF}_{4}\right]$} & $293.15-353.15$ & 15 & $-12.59 ;-22.79$ & 18.47 & 25 \\
\hline & $293.15-323.15$ & 7 & $9.72 ; 21.36$ & 15.28 & 38 \\
\hline \multirow[t]{8}{*}[\mathrm{C}_{2}\mathrm{mIm}]{$\left[\mathrm{Tf}_{2} \mathrm{~N}\right]$} & 293.15 & 1 & -4.25 & 4.25 & 9 \\
\hline & $293.15-353.15$ & 7 & $-9.95 ;-15.63$ & 14.03 & 13 \\
\hline & 303.15 & 1 & -13.08 & 13.08 & 20 \\
\hline & 298.15 & 1 & -3.79 & 3.79 & 10 \\
\hline & $293-343$ & 7 & $-9.03 ;-17.96$ & 13.72 & 18 \\
\hline & $293.15-353.15$ & 7 & $-16.72 ;-15.00$ & 15.72 & 21 \\
\hline & 293.1-353.1 & 8 & $-19.20 ;-15.23$ & 17.19 & 28 \\
\hline & $293.39-388.19$ & 11 & $-7.23 ;-22.13$ & 18.81 & 26 \\
\hline \multirow[t]{7}{*}[\mathrm{C}_{4}\mathrm{mIm}]{$\left[\mathrm{Tf}_{2} \mathrm{~N}\right]$} & 293.15 & 1 & 2.02 & 2.02 & 9 \\
\hline & $293.40-387.51$ & 11 & $-12.66 ; 13.55$ & 9.11 & 26 \\
\hline & $293.15-353.15$ & 7 & $-15.31 ;-6.20$ & 9.35 & 21 \\
\hline & $293.1-353.1$ & 8 & $-15.60 ;-5.69$ & 10.20 & 28 \\
\hline & $293.15-353.15$ & 13 & $-16.85 ;-9.05$ & 12.24 & 33 \\
\hline & 303.15 & 1 & -12.53 & 12.53 & 17 \\
\hline & $293.15-363.15$ & 15 & $-4.67 ; 6.86$ & 3.38 & 42 \\
\hline \multirow{5}{*}[\mathrm{C}_{6}\mathrm{mIm}]{$\left[\mathrm{Tf}_{2} \mathrm{~N}\right]$} & $293.1-353.1$ & 8 & $-4.23 ; 6.79$ & 2.89 & 28 \\
\hline & $293-343$ & 7 & $-1.83 ; 1.61$ & 0.95 & 18 \\
\hline & $293.15-373.15$ & 12 & $-3.44 ; 2.08$ & 1.88 & 40 \\
\hline & $293.15-353.15$ & 7 & $-0.82 ; 7.77$ & 4.73 & 21 \\
\hline & $293.15-393.15$ & 14 & $-4.01 ; 8.34$ & 2.85 & 35 \\
\hline \multirow[t]{2}{*}[\mathrm{C}_{8}\mathrm{mIm}]{$\left[\mathrm{Tf}_{2} \mathrm{~N}\right]$} & $293.15-353.15$ & 7 & $18.55 ; 20.14$ & 19.54 & 21 \\
\hline & $293.1-353.1$ & 8 & $18.54 ; 22.74$ & 19.94 & 28 \\
\hline$\left[\mathrm{C}_{4} \mathrm{mIm}\right]\left[\mathrm{CH}_{3} \mathrm{COO}\right]$ & $293-343$ & 7 & $-3.05 ; 2.77$ & 1.60 & 18 \\
\hline$\left[\mathrm{C}_{1} \mathrm{mIm}\right]\left[\mathrm{MeSO}_{4}\right]$ & $293.15-343.15$ & 7 & $6.05 ; 18.05$ & 12.89 & 14 \\
\hline$\left[\mathrm{C}_{4} \mathrm{mIm}\right]\left[\mathrm{MeSO}_{4}\right]$ & $293.15-343.15$ & 9 & $-10.01 ;-21.17$ & 15.71 & 37 \\
\hline \multirow[t]{6}{*}[\mathrm{C}_{2}\mathrm{mIm}]{$\left[\mathrm{EtSO}_{4}\right]$} & 298.15 & 1 & -1.39 & 1.39 & 22 \\
\hline & 298.15 & 1 & -1.39 & 1.39 & 30 \\
\hline & $298.15-348.15$ & 6 & $-0.75 ; 4.21$ & 2.56 & 27 \\
\hline & $298.15-328.15$ & 3 & $1.46 ; 2.16$ & 1.88 & 32 \\
\hline & $298.15-343.15$ & 10 & $1.46 ; 2.26$ & 1.88 & 23 \\
\hline & $296.80-388.19$ & 11 & $-3.55 ;-0.72$ & 1.77 & 26 \\
\hline$\left[\mathrm{C}_{2} \mathrm{mIm}\right]\left[\mathrm{CF}_{3} \mathrm{SO}_{3}\right]$ & $298.15-348.15$ & 6 & $-0.80 ; 18.64$ & 10.65 & 27 \\
\hline \multirow[t]{3}{*}[\mathrm{C}_{4}\mathrm{mIm}]{$\left[\mathrm{CF}_{3} \mathrm{SO}_{3}\right]$} & $293.15-323.15$ & 6 & $-10.45 ; 9.05$ & 4.54 & 16 \\
\hline & 293.15 & 1 & 9.05 & 9.05 & 9 \\
\hline & $293.1-353.1$ & 8 & $-12.31 ; 0.48$ & 4.54 & 28 \\
\hline$\left[\mathrm{C}_{4} \mathrm{Py}\right]\left[\mathrm{Tf}_{2} \mathrm{~N}\right]$ & $293.1-353.1$ & 8 & $-3.03 ; 0.76$ & 1.44 & 28 \\
\hline$\left[\mathrm{C}_{6} \mathrm{Py}\right]\left[\mathrm{Tf}_{2} \mathrm{~N}\right]$ & $293-343$ & 7 & $8.39 ; 17.05$ & 13.12 & 18 \\
\hline$\left[\mathrm{C}_{4} \mathrm{mPy}\right]\left[\mathrm{Tf}_{2} \mathrm{~N}\right]$ & $293-343$ & 7 & $-5.03 ;-0.98$ & 2.08 & 18 \\
\hline$\left[\mathrm{C}_{6} \mathrm{mPy}\right]\left[\mathrm{Tf}_{2} \mathrm{~N}\right]$ & $293-343$ & 7 & $11.08 ; 17.45$ & 14.71 & 18 \\
\hline$\left[\mathrm{C}_{4} \mathrm{mPy}\right]\left[\mathrm{BF}_{4}\right]$ & $298-343$ & 6 & $-13.56 ;-1.95$ & 7.42 & 18 \\
\hline$\left[\mathrm{C}_{2} \mathrm{Py}\right]\left[\mathrm{EtSO}_{4}\right]$ & $293-343$ & 7 & $-2.28 ; 2.50$ & 1.15 & 18 \\
\hline$\left[\mathrm{C}_{2} \mathrm{mPy}\right]\left[\mathrm{EtSO}_{4}\right]$ & $293-343$ & 7 & $-6.37 ; 2.90$ & 2.72 & 18 \\
\hline$\left[\mathrm{C}_{4} \mathrm{mPyr}\right]\left[\mathrm{Tf}_{2} \mathrm{~N}\right]$ & $293.1-353.1$ & 8 & $-15.44 ;-8.82$ & 11.12 & 28 \\
\hline & $301.0-343.0$ & 6 & $-12.52 ; 21.33$ & 9.53 & 31 \\
\hline TOTAL & $293.15-393.15$ & 482 & $-22.79 ; 22.77$ & 7.50 & \\
\hline
\end{tabular}


Table 2. Group Contributions Parameters $a_{\mathrm{i}, \eta}$, and $b_{i, \eta}$ in Eq. 3 for Temperature Range 293.15-393.15 K

\begin{tabular}{lcr}
\hline \multicolumn{1}{c}{ Species } & $a_{\mathrm{i}, \eta}$ & $b_{\mathrm{i}, \eta}(\mathrm{K})$ \\
\hline Cations & & \\
1,3-dimethylimidazolium (+) & -7.271 & 510.51 \\
1-methylpyridinium (+) & -7.541 & 587.66 \\
1,1-dimethylpyrrolidinium (+) & -7.512 & 601.77 \\
Anions & & \\
$\mathrm{PF}_{6}^{-}$ & -1.834 & 433.14 \\
$\mathrm{BF}_{4}^{-}$ & -1.680 & 288.05 \\
$\mathrm{Tf}_{2} \mathrm{~N}^{-}$ & -1.119 & 94.20 \\
$\mathrm{CH}_{3} \mathrm{COO}^{-}$ & -2.739 & 618.50 \\
$\mathrm{MeSO}_{4}^{-}$ & -1.580 & 339.90 \\
$\mathrm{EtSO}_{4}^{-}$ & -1.498 & 317.87 \\
$\mathrm{CF}_{3} \mathrm{SO}_{3}^{-}$ & -1.150 & 176.97 \\
$\mathrm{Groups}^{\mathrm{CH}_{2}}$ & & \\
$\mathrm{CH}_{3}$ & $-7.528 \times 10^{-2}$ & 40.92 \\
& $-1.450 \times 10^{-3}$ & 8.02 \\
\hline
\end{tabular}

$a_{i, \eta}$, and $b_{i, \eta}$ here estimated are presented in Table 2. Close to 500 data points for 25 ILs based on imidazolium-, pyridinium-, and pyrrolidinium cations with $\mathrm{PF}_{6}, \mathrm{BF}_{4}, \mathrm{Tf}_{2} \mathrm{~N}$, $\mathrm{CH}_{3} \mathrm{COO}, \mathrm{MeSO}_{4}, \mathrm{EtSO}_{4}$, or $\mathrm{CF}_{3} \mathrm{SO}_{3}$ as anions, covering wide ranges of temperature, 293.15-393.15 K and viscosity, 0.004-1.065 Pa s, ${ }^{9-42}$ were used in this study.

The VTF equation was fitted to the experimental data available for each IL studied. From these initial estimates, it was, surprisingly, found that $\mathrm{T}_{0 \eta}$ was similar for all the ILs studied, with a value close to $165 \mathrm{~K}$. From a simultaneous optimization of the entire database using the objective function described in Eq. 4 it was found that the optimum value of $T_{0 \eta}$ is $165.06 \mathrm{~K}$.

$$
\text { O.F. }=\sum_{i=1}^{N_{\mathrm{p}}}\left[\left(\exp \left(\ln A_{\eta}+\frac{B_{\eta}}{\left(T-T_{0 \eta}\right)}\right)-\eta_{\exp }\right)^{2}\right]_{i}
$$

With the relative average deviation (RD) defined as,

$$
\mathrm{RD}(\%)=\frac{100 \times \sum_{i=1}^{N_{\mathrm{p}}}\left|\left(\eta_{\text {cal }}-\eta_{\exp }\right) / \eta_{\exp }\right|_{i}}{N_{\mathrm{p}}}
$$

where subscripts cal and exp denote calculated and experimental property respectively, $N_{\mathrm{p}}$ represents the number of available data points for each system reported in Table 1.

Taking $T_{0 \eta}$ as a constant valid for all ILs estimates of the values of $a_{i, \eta}$ and $b_{i, \eta}$ for each group are then obtained using Eqs. 3 and 4 .

As shown in Figure 1a, a remarkable agreement is observed between the calculated and the experimental viscosity data, by using VTF equation (Eq. 2) with $T_{0 \eta}=$ $165.06 \mathrm{~K}$ and using group contribution parameters $a_{i, \eta}$ and $b_{i, \eta}$ (Table 2) for imidazolium-, pyridinium-, and pyrrolidinium-based ILs containing $\mathrm{PF}_{6}, \mathrm{BF}_{4}, \mathrm{Tf}_{2} \mathrm{~N}, \mathrm{CH}_{3} \mathrm{COO}$, $\mathrm{MeSO}_{4}, \mathrm{EtSO}_{4}$, and $\mathrm{CF}_{3} \mathrm{SO}_{3}$ anions in a wide range of temperature and viscosity. Viscosities of ILs having imidazolium based cations increases in the series: $\left[\mathrm{Tf}_{2} \mathrm{~N}\right]<\left[\mathrm{CF}_{3} \mathrm{SO}_{3}\right]<$ $\left[\mathrm{BF}_{4}\right]<\left[\mathrm{EtSO}_{4}\right]<\left[\mathrm{MeSO}_{4}\right]<\left[\mathrm{PF}_{6}\right]<\left[\mathrm{CH}_{3} \mathrm{COO}\right] .{ }^{6}$ For ILs having a common anion and a similar alkyl chain length on the cation, the viscosity increases with cation following the order: $[\mathrm{Im}]<[\mathrm{py}]<[\mathrm{pyr}] .^{6}$

The calculated viscosity $\left(\eta_{\text {cal }}\right)$ of the ILs studied displays a good agreement with the corresponding experimental vis- cosity $\left(\eta_{\text {exp }}\right)$, where $\ln \eta_{\text {cal }}=(0.9647 \pm 0.0043) \cdot \ln \eta_{\text {exp }}\left(R^{2}\right.$ $=0.9907$ at $95 \%$ level of confidence). Relative deviations between the calculated and experimental viscosity data as a function of experimental viscosity for all data points used in the current study are shown in Figure 1b. For 482 data points of $25 \mathrm{ILs}$ available in literature, the overall RD is $7.50 \%$ with a maximum deviation smaller than $23 \%$. From these $49.8 \%$ of the estimated viscosities were within relative deviation of $0.00-5.00 \%, 16.2 \%$ within $5.001-10.00 \%$, $16.8 \%$ within $10.001-15.00 \%, 12.4 \%$ within $15.001-20.00 \%$, and only $4.8 \%$ of the estimated viscosities having larger than $20.0 \%$ deviation. The maximum relative deviation is $22.79 \%$ observed for [ $\left.\mathrm{C}_{8} \mathrm{mim}\right][\mathrm{BF} 4]$ (1-octyl-3-methylimidazolium tetrafluoroborate) at $293.15 \mathrm{~K}^{38}$ At present stage, rejection of doubtful experimental data is not possible due to the

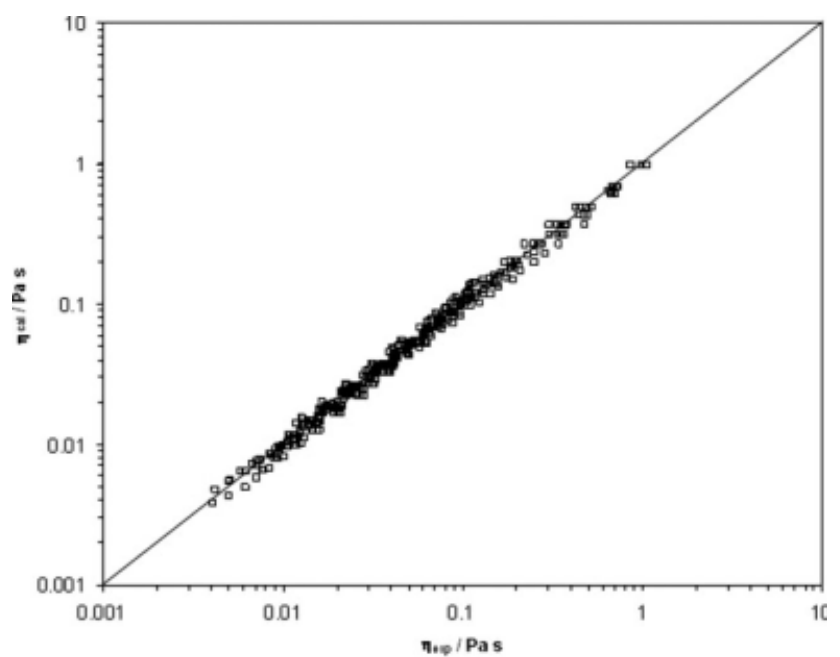

(a)

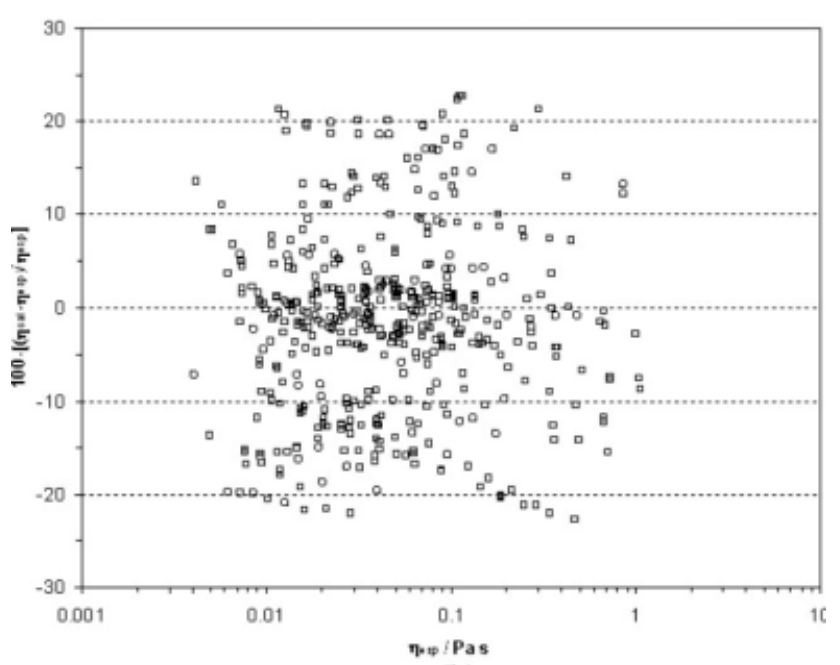

(b)

Figure 1. (a) Linear relationship between experimental and calculated viscosity using Eq. 2 and (b) relative deviations between the calculated and experimental viscosity data as a function of experimental viscosity for imidazolium-, pyridinium-, and pyrrolidinium-based ionic liquids in the current study. 
Table 3. Prediction of Electrical Conductivities of Imidazolium-, Pyridinium-, Pyrrolidinium-, and Ammonium-Based Ionic Liquids

\begin{tabular}{|c|c|c|c|c|c|}
\hline Ionic Liquid & $\begin{array}{l}\text { Temperature } \\
\text { Range }(\mathrm{K})\end{array}$ & $\begin{array}{c}\text { Data } \\
\text { Points }\end{array}$ & Relative Deviation (range) (\%) & $\begin{array}{c}\text { Average Absolute } \\
\text { Relative Deviation }(\%)\end{array}$ & Reference \\
\hline \multirow[t]{3}{*}[\mathrm{C}_{4}\mathrm{mIm}]{$\left[\mathrm{PF}_{6}\right]$} & $288.15-323.15$ & 5 & $-5.82 ; 1.04$ & 2.62 & 46 \\
\hline & $263.1-373.1$ & 10 & $-4.61 ; 8.68$ & 3.58 & 28 \\
\hline & 298.14-353.12 & 17 & $-2.20 ; 4.28$ & 2.31 & 47 \\
\hline \multirow{2}{*}[\mathrm{C}_{2}\mathrm{mIm}]{$\left[\mathrm{BF}_{4}\right]$} & 298.1 & 1 & 1.38 & 1.38 & 15 \\
\hline & $258.1-433.1$ & 36 & $-15.93 ; 1.89$ & 3.27 & 48 \\
\hline \multirow{2}{*}[\mathrm{C}_{4}\mathrm{mIm}]{$\left[\mathrm{BF}_{4}\right]$} & 298.1 & 1 & 5.27 & 5.27 & 15 \\
\hline & $263.1-373.1$ & 10 & $-0.30 ; 16.01$ & 4.67 & 28 \\
\hline \multirow{2}{*}[\mathrm{C}_{1}\mathrm{mIm}]{$\left[\mathrm{Tf}_{2} \mathrm{~N}\right]$} & $263.15-373.15$ & 12 & $-11.86 ; 3.89$ & 4.75 & 21 \\
\hline & $293.1-373.1$ & 7 & $-10.33 ; 4.00$ & 5.07 & 28 \\
\hline \multirow{3}{*}[\mathrm{C}_{2}\mathrm{mIm}]{$\left[\mathrm{Tf}_{2} \mathrm{~N}\right]$} & $288.15-323.15$ & 5 & $-9.89 ; 1.77$ & 4.12 & 46 \\
\hline & $263.15-373.15$ & 12 & $-14.86 ; 13.33$ & 8.57 & 21 \\
\hline & 263.1-373.1 & 10 & $-15.92 ; 15.98$ & 8.08 & 28 \\
\hline \multirow{3}{*}[\mathrm{C}_{4}\mathrm{mIm}]{$\left[\mathrm{Tf}_{2} \mathrm{~N}\right]$} & $288.15-323.15$ & 5 & $-10.21 ;-4.55$ & 7.95 & 46 \\
\hline & $263.15-373.15$ & 12 & $-7.17 ; 12.26$ & 5.98 & 21 \\
\hline & $263.1-373.1$ & 10 & $-7.97 ; 15.92$ & 5.38 & 28 \\
\hline \multirow[t]{4}{*}[\mathrm{C}_{6}\mathrm{mIm}]{$\left[\mathrm{Tf}_{2} \mathrm{~N}\right]$} & $288.15-323.15$ & 5 & $-1.74 ; 2.54$ & 1.39 & 46 \\
\hline & $263.15-373.15$ & 12 & $-10.07 ; 9.33$ & 5.34 & 21 \\
\hline & $263.1-373.1$ & 10 & $-6.76 ; 11.09$ & 5.34 & 28 \\
\hline & $278.15-323.15$ & 9 & $-3.08 ; 3.68$ & 1.52 & 35 \\
\hline \multirow[t]{2}{*}[\mathrm{C}_{8}\mathrm{mIm}]{$\left[\mathrm{Tf}_{2} \mathrm{~N}\right]$} & $263.15-373.15$ & 12 & $-16.01 ; 10.13$ & 6.93 & 21 \\
\hline & $263.1-373.1$ & 10 & $-13.71 ; 7.03$ & 6.39 & 28 \\
\hline$\left[\mathrm{C}_{2} \mathrm{mIm}\right]\left[\mathrm{EtSO}_{4}\right]$ & $258.1-433.1$ & 36 & $-15.31 ; 14.93$ & 8.28 & 48 \\
\hline$\left[\mathrm{C}_{4} \mathrm{mIm}\right]\left[\mathrm{CF}_{3} \mathrm{SO}_{3}\right]$ & $263.1-373.1$ & 10 & $-3.48 ; 1.64$ & 1.21 & 28 \\
\hline$\left[\mathrm{C}_{4} \mathrm{mIm}\right]\left[\mathrm{Pf}_{2} \mathrm{~N}\right]$ & $263.1-373.1$ & 10 & $-4.76 ; 0.58$ & 1.87 & 28 \\
\hline$\left[\mathrm{C}_{4} \mathrm{mIm}\right]\left[\mathrm{CF}_{3} \mathrm{COO}\right]$ & $263.1-373.1$ & 10 & $-2.82 ; 5.16$ & 1.87 & 28 \\
\hline$\left[\mathrm{C}_{4} \mathrm{Py}\right]\left[\mathrm{Tf}_{2} \mathrm{~N}\right]$ & $263.1-373.1$ & 10 & $-4.07 ; 5.05$ & 2.36 & 28 \\
\hline$\left[\mathrm{C}_{4} \mathrm{mPyr}\right]\left[\mathrm{Tf}_{2} \mathrm{~N}\right]$ & $263.1-373.1$ & 10 & $-2.32 ; 3.46$ & 1.41 & 28 \\
\hline$[\mathrm{Am}(4) 111]\left[\mathrm{Tf}_{2} \mathrm{~N}\right]$ & $263.1-373.1$ & 10 & $-3.59 ; 5.39$ & 2.66 & 28 \\
\hline TOTAL & $258.1-433.1$ & 307 & $-16.01 ; 16.01$ & 4.57 & \\
\hline
\end{tabular}

limited amount of experimental data currently available and the large discrepancies in experimental viscosity values reported in literature among authors, which may be due to impurities like water and halogen ions present in IL samples, or the experimental method adapted.

The predictive capability of the group contribution method here developed for IL viscosity will be further checked below by its potential to correlate with equivalent conductivity and the self-diffusion coefficient using fractional forms of Walden rule ${ }^{114}$ and Stokes-Einstein relation, ${ }^{115}$ respectively, as will be discussed in subsequent sections of this work.

\section{Electrical conductivity}

Electrical conductivity $(\lambda)$ or specific conductivity measures the ability of a material to conduct an electric current. It is defined as the ratio of the current density to the electric field strength. Electrical conductivity is the most important property for chemists and engineers to understand the structure of ionic chemical systems, to control and to design industrial processes, and in the development of electrochemical devices such as high energy batteries. As applications of ILs are rising exponentially in several scientific fields including electro chemistry, it is important to develop a predictive method for the electrical conductivity of ILs which will be used, when experimentally measured electrical conductivity of ILs are not available, to establish if the electrical conductivities are within acceptable limiting values defined in design specifications.

A database of experimental electrical conductivity $(\lambda)$ available from the open literature was collected and is reported in Table 3. A global number of 300 data points for 15 ILs based on imidazolium-, pyridinium-, pyrrolidinium-, and ammonium-based cations with $\mathrm{PF}_{6}, \mathrm{BF}_{4}, \mathrm{Tf}_{2} \mathrm{~N}, \mathrm{EtSO}_{4}$, $\mathrm{CF}_{3} \mathrm{SO}_{3}, \mathrm{Pf}_{2} \mathrm{~N}$, or $\mathrm{CF}_{3} \mathrm{COO}$ as anions, covering wide ranges of temperature, 258.1-433.15 $\mathrm{K}$ and electrical conductivity, $0.01-12.68 \mathrm{~S} \mathrm{~m}^{-1},{ }^{15,21,28,35,46-48}$ were used in this study.

A VTF type equation (Eq. 6), similar to what was used for the viscosity, will be here applied to the correlation of the electrical conductivity of ILs.

$$
\ln \lambda=\ln A_{\lambda}+\frac{B_{\lambda}}{\left(T-T_{0 \lambda}\right)}
$$

where $A_{\lambda}, B_{\lambda}$, and $T_{0 \lambda}$ are adjustable parameters, from which $A_{\lambda}$ and $B_{\lambda}$ can be obtain by a group contribution method.

$$
A_{\lambda}=\sum_{i=1}^{k} n_{i} a_{i, \lambda} \quad B_{\lambda}=\sum_{i=1}^{k} n_{i} b_{i, \lambda}
$$

where $n_{i}$ is the number of groups of type $i$ and $k$ is the total number of different of groups in the molecule, and the parameters $a_{i, \lambda}$ and $b_{i, \lambda}$ here estimated for the ILs studied are presented in Table 4 . The estimation of the parameters followed an approach similar to what was described above for the viscosities. Again, from the correlation of the individual IL electrical conductivities, it was found that $T_{0 \lambda}$ presented a value for all studied ILs close to $165 \mathrm{~K}$, surprisingly similar to $T_{0 \eta}$ which clearly indicates that these values have a physical meaning. The $T_{0 \lambda}$ value was thus fixed to a value identical to $T_{0 \eta}\left(T_{0 \eta}=T_{0 \lambda}=165.06 \mathrm{~K}\right)$. The circa 300 experimental electrical conductivity data points of $15 \mathrm{ILs}$ 
Table 4. Group Contributions Parameters $a_{i, \lambda}$, and $b_{i, \lambda}$ in Eq. 7 for Temperature Range 258.15-433.15 K

\begin{tabular}{lrr}
\hline \multicolumn{1}{c}{ Species } & $a_{i, \lambda}$ & $b_{i, \lambda}(\mathrm{K})$ \\
\hline Cations & & \\
1,3-dimethylimidazolium (+) & 78.0 & -573.7 \\
1-ethyl-3-methylimidazolium (+) & 28.1 & -454.0 \\
1-methylpyridinium (+) & 69.7 & -581.0 \\
1,1-dimethylpyrrolidinium (+) & 62.5 & -588.4 \\
Tetramethyl ammonium (+) & 89.4 & -670.2 \\
Anions & & \\
$\mathrm{PF}_{6}^{-}$ & 117.3 & -278.6 \\
$\mathrm{BF}_{4}^{-}$ & 85.8 & -129.4 \\
$\mathrm{Tf}_{2} \mathrm{~N}^{-}$ & 10.1 & -46.4 \\
$\mathrm{CF}_{3} \mathrm{SO}_{3}^{-}$ & 9.0 & -76.7 \\
$\mathrm{EtSO}_{4}^{-}$ & 120.2 & -356.5 \\
$\mathrm{Pf}_{2} \mathrm{~N}^{-}$ & 3.0 & -161.1 \\
$\mathrm{CF}_{3} \mathrm{COO}^{-}$ & 51.6 & -123.9 \\
$\mathrm{Group}^{\mathrm{CH}_{2}}$ & & \\
& 0.1 & -36.1 \\
\hline
\end{tabular}

available was then used to obtain the values of the group parameter $a_{i, \lambda}$, and $b_{i, \lambda}$ reported in Table 4 , by minimization of the objective function

$$
\text { O.F. }=\sum_{i=1}^{N_{\mathrm{p}}}\left[\left(\exp \left(\ln A_{\lambda}+\frac{B_{\lambda}}{\left(T-T_{0 \lambda}\right)}\right)-\lambda_{\exp }\right)^{2}\right]_{i}
$$

The calculated electrical conductivity $\left(\lambda_{\text {cal }}\right)$, by using VTF equation (Eq. 6) with $T_{0 \lambda}=165.06 \mathrm{~K}$ and using group contribution parameters $a_{i, \lambda}$, and $b_{i, \lambda}$ (Table 4) for imidazolium-, pyridinium-, pyrrolidinium-, and ammonium based ILs having $\mathrm{PF}_{6}, \mathrm{BF}_{4}, \mathrm{Tf}_{2} \mathrm{~N}, \mathrm{EtSO}_{4}, \mathrm{CF}_{3} \mathrm{SO}_{3}, \mathrm{Pf}_{2} \mathrm{~N}$, or $\mathrm{CF}_{3} \mathrm{COO}$ as anions, are in good agreement with the corresponding experimental electrical conductivity $\left(\lambda_{\exp }\right)$, as shown in Figure 2a; where $\lambda_{\text {cal }}=(0.9974 \pm 0.0022) \cdot \lambda_{\exp }\left(R^{2}=0.9985\right.$ at $95 \%$ level of confidence). Relative deviations between the calculated and experimental electrical conductivity data as a function of experimental electrical conductivity for all data points used in the current study are shown in Figure 2b. For 307 data points of 15 ILs available in literature, the overall RD is $4.57 \%$ with a maximum deviation of the order of $16 \%$. From these $38.1 \%$ of the estimated electrical conductivities were within relative deviation of $0.00-2.00 \%, 25.7 \%$ within $2.001-$ $5.00 \%, 22.8 \%$ within $5.001-10.00 \%$, and only $13.4 \%$ of the estimated electrical conductivities having larger than $10.0 \%$ deviation. The maximum relative deviation of $16.01 \%$ is observed for [ $\left.\mathrm{C}_{4} \mathrm{mim}\right][\mathrm{BF} 4$ (1-butyl-3-methylimidazolium tetrafluoroborate) at $263.1 \mathrm{~K}^{28}$ and for $\left[\mathrm{C}_{8}\right.$ mim] [Tf2N] (1octyl-3-methylimidazolium bis(trifluoromethanesulfonyl) amide) at $263.15 \mathrm{~K}^{21}$ Water content present in IL sample may increase its electrical conductivity significantly ${ }^{116}$ which may be a possible reason for some of the larger deviations observed in the calculated electrical conductivity.

For ILs having $\left[\mathrm{C}_{4} \text { mim }\right]^{+}$(1-butyl-3-methylimidazolium cation), electrical conductivity is increased with anion following the order $\left[\mathrm{Pf}_{2} \mathrm{~N}\right] \leq\left[\mathrm{PF}_{6}\right]<\left[\mathrm{CF}_{3} \mathrm{SO}_{3}\right]<\left[\mathrm{Tf}_{2} \mathrm{~N}\right] \leq$ $\left[\mathrm{CH}_{3} \mathrm{COO}\right]<\left[\mathrm{BF}_{4}\right]$. Electrical conductivity decreases with the increase of alkyl chain length on imidazolium cation and this decrease is more pronounced at higher temperatures. For ILs having a common anion and a similar alkyl chain length on the cation, the electrical conductivity, behaving opposite to viscosity, decreases with cation following the order: [Im] $>[\mathrm{Py}]>[\mathrm{Pyr}]$. However more experimental data and theoretical studies are required to fully understand the influence of cation and anion on the electrical conductivity of ILs.

Generally, high conductive liquids have high fluidity, as would be expected from the Walden rule ${ }^{114}$ connecting the ionic mobility to the frictional resistance of ion to its movement offered by the liquid viscosity, under the electrochemical force. The relationship between viscosity and conductance in terms of the fractional Walden rule can be written as:

$$
\Lambda \cdot \eta^{a}=\text { constant }
$$

where $\Lambda$ is equivalent conductivity and $\alpha$ is a constant between zero and unity. The $\log \Lambda$ versus $\log \eta^{-1}$ plot is shown in Figure ${ }^{3}$ using reciprocal poise $\left(\mathrm{P}^{-1}\right)$ and $\mathrm{S} \mathrm{cm}^{2} \mathrm{~mol}^{-1}$ as the units for fluidity and equivalent conductivity, respectively. For
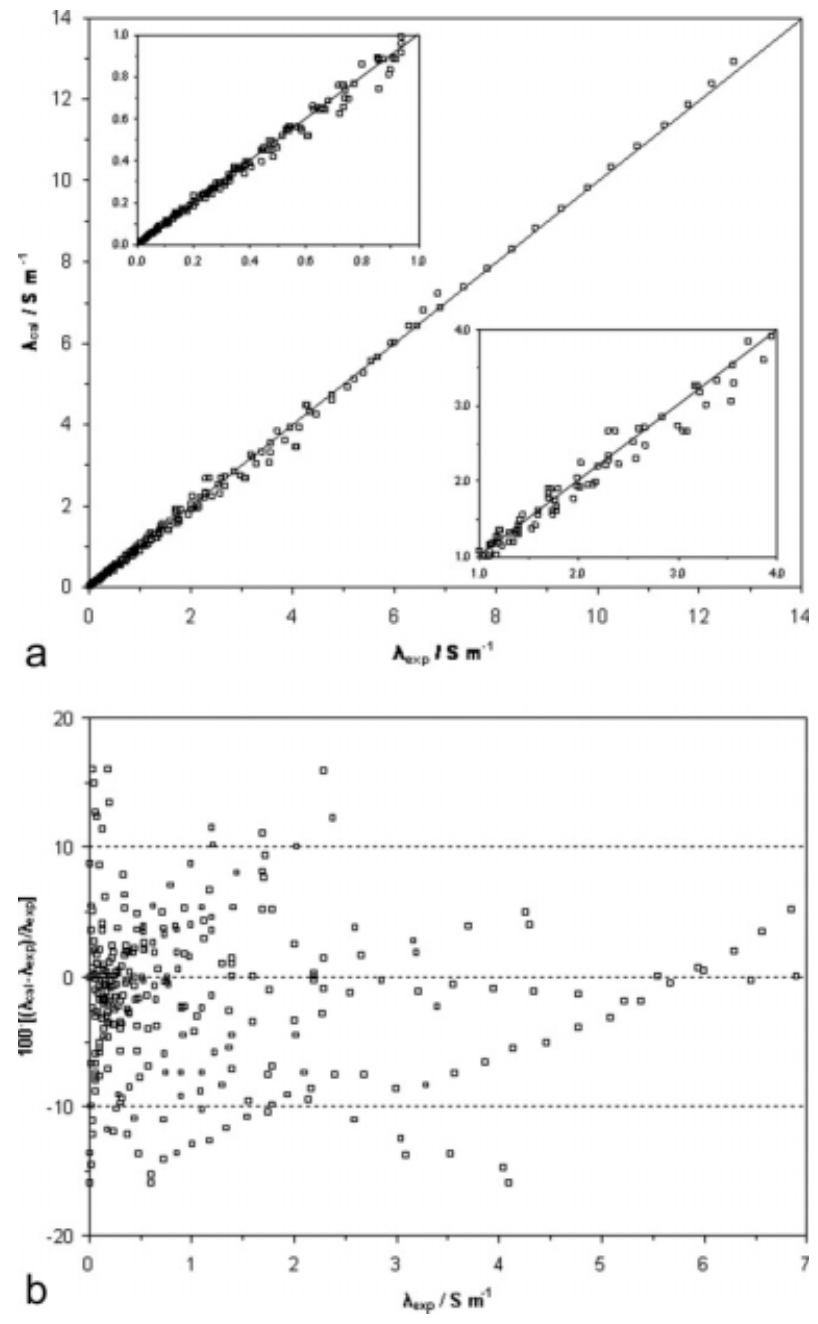

Figure 2. (a) Linear relationship between experimental and calculated electrical conductivity using Eq. 6 and (b) relative deviations between the calculated and experimental electrical conductivity as a function of experimental electrical conductivity for imidazolium-, pyridinium-, pyrrolidinium-, and ammonium-based ionic liquids in the current study. 


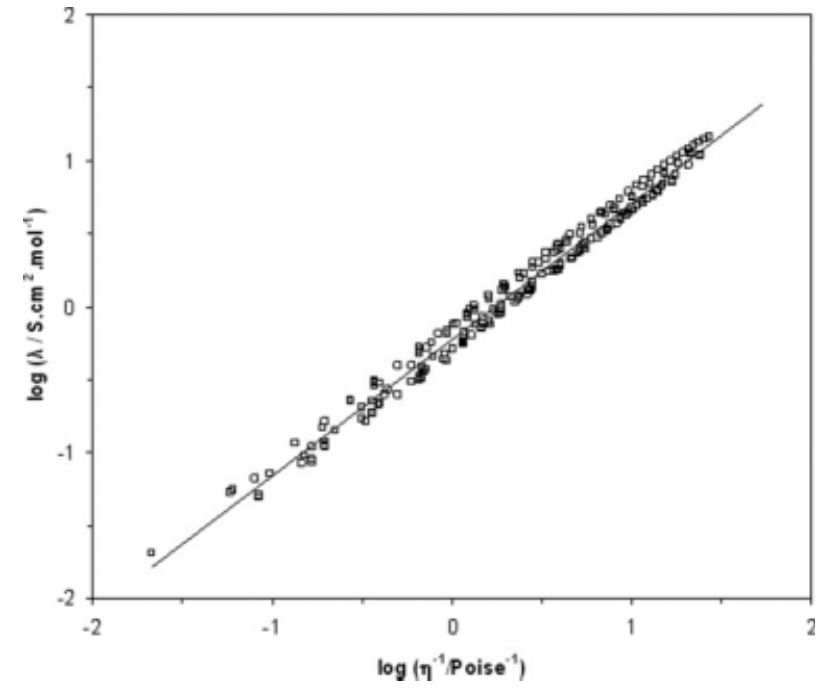

Figure 3. Walden plot showing the behavior of equivalent conductivity of ionic liquids expected from precise correlation with their viscosity.

Experimental electrical conductivity data collected from literature are converted into equivalent conductivity using density calculated from our previous model (Ref. 4), and fluidity is obtained as the reciprocal of viscosity from group contribution method developed in this work.

the chosen units, the "ideal" Walden line runs from corner to corner of a square diagram. The Walden plot can also be useful to understand the relationship between electrical conductivity and vapor pressure. ${ }^{117}$ For the purpose of Figure 3, experimental electrical conductivity data collected from literature ${ }^{15,21,28,35,46-48}$ are converted into equivalent conductivity using density calculated from our previous model, ${ }^{4}$ and fluidity is obtained as the reciprocal of viscosity from group contribution method developed in this work. In the log-log plot (Figure 3); the slope $(\alpha)$ of the Walden line is obtained as $0.935 \pm 0.008$. From the plot it is clear that equivalent conductance $(\Lambda)$ can be predicted from precise correlation with viscosity $(\eta)$, using linear relation: $\log \Lambda=(0.935 \pm$ $0.008) \cdot \log \eta^{-1}-(0.226 \pm 0.005)$ and, as usual, the conductivity decreases with viscosity increase. This correlation also supports the predictive ability of the model for density previously proposed ${ }^{4}$ and the group contribution method here developed for viscosity.

\section{Self-diffusion coefficient}

Self-diffusion coefficient $(D)$ is one of the most important transport properties of fluids, which is required in the framework of chemical reaction kinetics and process design. It is related to viscosity in terms of the fractional form of the Stokes-Einstein relation ${ }^{115}$ according to which the self-diffusion coefficient is proportional to the ratio of temperature and viscosity and can be written as:

$$
D \cdot(\eta / T)^{\beta}=\text { constant }
$$

where $\beta$ is a constant.

Experimental self-diffusion coefficient $(D)$ data of ILs are still scarce in the open literature. The data available were collected to evaluate the relation between self-diffusion coefficient $(D)$ and viscosity $(\eta)$ as shown in Figure 4. For this purpose the viscosity was calculated using the group contribution method proposed above. For 45 data points for 5 ILs based on imidazolium cation with $\mathrm{BF}_{4}$ or $\mathrm{Tf}_{2} \mathrm{~N}$ as anion, covering wide ranges of temperature, $263.15-353.15 \mathrm{~K}$ and self-diffusion coefficient, $2.43 \times 10^{-12}-3.71 \times 10^{-10} \mathrm{~m}^{2}$ $\mathrm{s}^{-1},{ }^{21,118}$ a very good linear correlation is observed with $T / \eta$, as shown in Figure 4; where

$$
\begin{aligned}
D \cdot 10^{12}=(6.995 \pm 0.061) \cdot(T / \eta) \\
\left(R^{2}=0.997 \text { at } 95 \% \text { level of confidence }\right)
\end{aligned}
$$

This correlation further supports the predictive ability of group contribution method here proposed for the viscosity of ILs and allows an estimation of the self-diffusion coefficient of ILs based on viscosity data.

It would be interesting to correlate the ionic diffusivity with conductivity through Nernst-Einstein equation, but the limited amount of experimental data available restricted such development at this point. We are confident that such correlation for ILs will be possible when an adequate amount of experimental data will become available.

\section{Thermal conductivity}

Thermal conductivity measures the ability of a material to conduct heat. It depends on many properties of a material, particularly on its structure and temperature. The knowledge of the thermal conductivity is important to obtain the heat transfer coefficient of fluids which is essential for the design of heat transfer fluid and equipments. ${ }^{119}$ Among the different transport properties, thermal conductivity is one of the most difficult to estimate using predictive methods.

The database of experimental thermal conductivity $(\kappa)$ available in the open literature, reported in Table 5, is limited. The 107 data points available, for 16 ILs based on

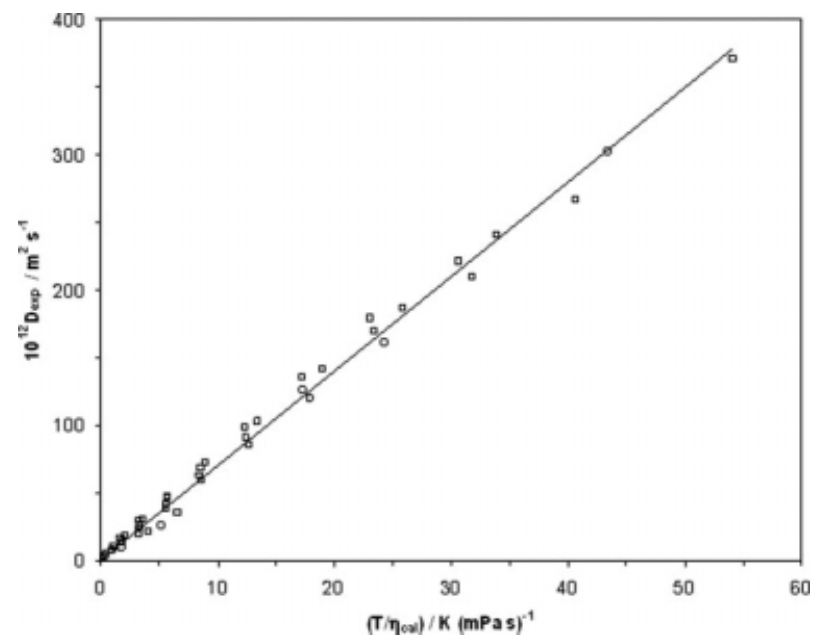

Figure 4. Plot showing the validity of the fractional form of the Stokes-Einstein relation for the studied ionic liquids.

Experimental self-diffusion coefficient data collected from literature and viscosity obtained from group contribution method developed in this work. 
Table 5. Prediction of Thermal Conductivities of Imidazolium-, Pyrrolidinium-, and Phosphonium-Based Ionic Liquids

\begin{tabular}{|c|c|c|c|c|}
\hline Ionic Liquid & $\begin{array}{c}\text { Temperature } \\
\text { Range }(\mathrm{K})\end{array}$ & $\begin{array}{c}\text { Data } \\
\text { Points }\end{array}$ & $\begin{array}{c}\text { Average Absolute } \\
\text { Relative Deviation }(\%)\end{array}$ & Reference \\
\hline$\left[\mathrm{C}_{4} \mathrm{mIm}\right]\left[\mathrm{PF}_{6}\right]$ & 294.9-335.1 & 3 & 0.15 & 44 \\
\hline$\left[\mathrm{C}_{6} \mathrm{mIm}\right]\left[\mathrm{PF}_{6}\right]$ & 294.9-335.2 & 3 & 0.22 & 44 \\
\hline$\left[\mathrm{C}_{8} \mathrm{mIm}\right]\left[\mathrm{PF}_{6}\right]$ & 294.9-335.1 & 3 & 0.26 & 44 \\
\hline$\left[\mathrm{C}_{2} \mathrm{mIm}\right][\mathrm{BF} 4]$ & $300-390$ & 10 & 3.07 & 43 \\
\hline$[\mathrm{C} 4 \mathrm{mIm}][\mathrm{BF} 4]$ & $300-390$ & 10 & 2.49 & 43 \\
\hline$\left[\mathrm{C}_{2} \mathrm{mIm}\right]\left[\mathrm{Tf}_{2} \mathrm{~N}\right]$ & $293-353$ & 7 & 1.58 & 45 \\
\hline \multirow[t]{2}{*}[\mathrm{C}4\mathrm{mIm}]{$\left[\mathrm{Tf}_{2} \mathrm{~N}\right]$} & $293-353$ & 7 & 1.26 & 45 \\
\hline & 298.15 & 1 & 2.06 & 42 \\
\hline$\left[\mathrm{C}_{6} \mathrm{mIm}\right]\left[\mathrm{Tf}_{2} \mathrm{~N}\right]$ & $293-353$ & 7 & 1.40 & 45 \\
\hline$\left[\mathrm{C}_{8} \mathrm{mIm}\right]\left[\mathrm{Tf}_{2} \mathrm{~N}\right]$ & $293-353$ & 7 & 1.09 & 45 \\
\hline$\left[\mathrm{C}_{10} \mathrm{mIm}\right]\left[\mathrm{Tf}_{2} \mathrm{~N}\right]$ & $293-353$ & 7 & 0.78 & 45 \\
\hline$\left[\mathrm{C}_{3} \mathrm{mmIm}\right]\left[\mathrm{Tf}_{2} \mathrm{~N}\right]$ & $300-390$ & 10 & 0.20 & 43 \\
\hline$\left[\mathrm{C}_{2} \mathrm{mIm}\right][\mathrm{EtSO} 4]$ & $293-353$ & 7 & 0.15 & 45 \\
\hline$[\mathrm{C} 4 \mathrm{mIm}]\left[\mathrm{CF}_{3} \mathrm{SO}_{3}\right]$ & $293-353$ & 7 & 0.15 & 45 \\
\hline$[\mathrm{THTDPh}]\left[\mathrm{Tf}_{2} \mathrm{~N}\right]$ & $293-353$ & 7 & 0.66 & 45 \\
\hline [THTDPh][Cl] & $293-353$ & 7 & 0.24 & 45 \\
\hline$[\mathrm{C} 4 \mathrm{mPyr}]\left[\mathrm{Tf}_{2} \mathrm{~N}\right]$ & $293-353$ & 7 & 0.19 & 45 \\
\hline TOTAL & $293-390$ & 107 & 1.06 & \\
\hline
\end{tabular}

imidazolium-, pyrrolidinium-, and phosphonium based cations with $\mathrm{PF}_{6}, \mathrm{BF}_{4}, \mathrm{Tf}_{2} \mathrm{~N}, \mathrm{EtSO}_{4}, \mathrm{CF}_{3} \mathrm{SO}_{3}$, or $\mathrm{Cl}$ as anions, covering wide range of temperature, $293-390 \mathrm{~K}$ and thermal conductivity, $0.124-0.199 \mathrm{~W} \mathrm{~m}^{-1} \mathrm{~K}^{-1},{ }^{42-45}$ were used in this study. From the experimental thermal conductivity, it was observed that the thermal conductivity is weakly dependent on temperature, and could be fitted with a linear correlation of the form:

$$
\kappa=A_{\kappa}-B_{\kappa} T
$$

where $T$ is temperature in $\mathrm{K}$, and $A_{\kappa}$ and $B_{k}$ are fitting parameters that can be obtained from a group contribution approach as

$$
A_{\kappa}=\sum_{i=1}^{k} n_{i} a_{i, \kappa} \quad B_{\kappa}=\sum_{i=1}^{k} n_{i} b_{i, \kappa}
$$

where $n_{i}$ is the number of groups of type $i$ and $k$ is the total number of different groups in the molecule, and the parameters $a_{i, \kappa}$, and $b_{i, \kappa}$ here estimated for ILs studied are given in Table

Table 6. Group Contributions Parameters $a_{i, \kappa}$ and $b_{i}, \kappa$ in Eq. 13 for Temperature Range 293-390 K

\begin{tabular}{lcc}
\hline \multicolumn{1}{c}{ Species } & $a_{\mathrm{i}, \kappa}$ & $b_{i, \kappa}\left(\mathrm{K}^{-1}\right)$ \\
\hline Cations & & \\
1,3-dimethylimidazolium (+) & 0.1356 & $1.564 \times 10^{-5}$ \\
1,1-dimethylpyrrolidinium (+) & 0.1325 & $1.668 \times 10^{-5}$ \\
Tetramethyl phosphonium (+) & 0.1503 & $3.230 \times 10^{-5}$ \\
Anions & & \\
$\mathrm{PF}_{6}^{-}$ & 0.0173 & $9.088 \times 10^{-6}$ \\
$\mathrm{BF}_{4}^{-}$ & 0.0874 & $8.828 \times 10^{-5}$ \\
$\mathrm{Tf}_{2} \mathrm{~N}^{-}$ & 0.0039 & $2.325 \times 10^{-5}$ \\
$\mathrm{CF}_{3} \mathrm{SO}_{3}^{-}$ & 0.0305 & $5.284 \times 10^{-5}$ \\
$\mathrm{EtSO}_{4}^{-}$ & 0.0700 & $6.552 \times 10^{-5}$ \\
$\mathrm{Cl}^{-}$ & 0.0166 & $1.000 \times 10^{-5}$ \\
$\mathrm{Groups}^{\mathrm{CH}}$ & & \\
$\mathrm{CH}_{3}$ & 0.0010 & $2.586 \times 10^{-6}$ \\
& 0.0042 & $7.768 \times 10^{-6}$ \\
\hline
\end{tabular}

6. According to Eq. 12, a plot of $\kappa$ versus $T$ gives the values of $B_{k}$ as slope and $A_{k}$ as intercept. After an initial correlation of each individual IL using Eq. 12 an approach similar to what was used previously for the other properties discussed above was followed to obtain the optimum values of the group contribution parameters $a_{i, \kappa}$ and $b_{i, \kappa}$ reported in Table 6 by minimization of the objective function below

$$
\text { O.F. }=\sum_{i=1}^{N_{\mathrm{p}}}\left[\left(\left(A_{\kappa}-B_{\kappa} T\right)-\kappa_{\exp }\right)^{2}\right]_{i}
$$

The calculated thermal conductivity ( $\kappa_{\text {cal }}$ ) using the group contribution parameters $a_{i, \kappa}$, and $b_{i, \kappa}$ reported in Table 6 for imidazolium-, pyrrolidinium-, and phosphonium based ILs

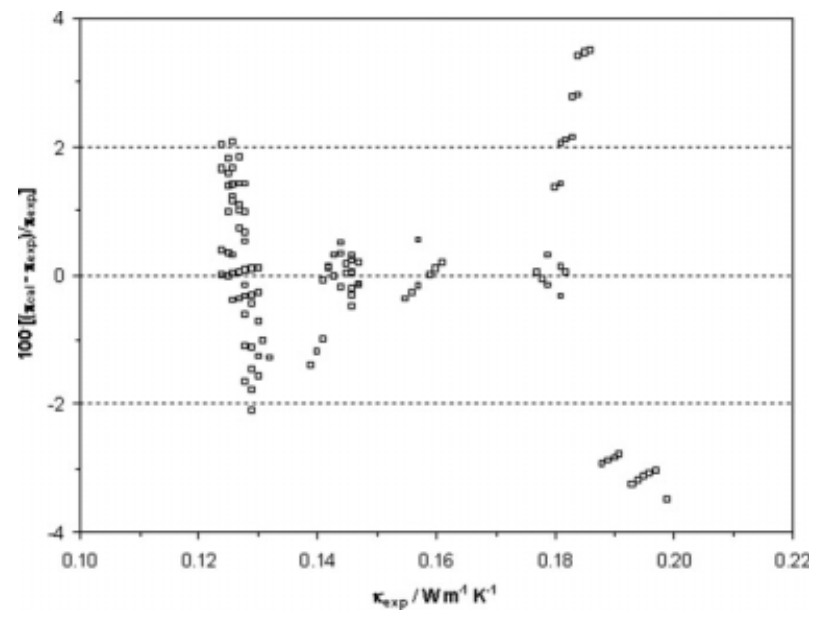

Figure 5. Relative deviations between the calculated and experimental thermal conductivity as a function of experimental thermal conductivity for imidazolium-, pyrrolidinium-, and phosphonium-based ionic liquids in the current study. 
Table 7. Prediction of Refractive Index of Imidazolium-Based Ionic Liquids

\begin{tabular}{|c|c|c|c|c|c|c|c|}
\hline $\begin{array}{l}\text { Temperature } \\
\text { Range }(\mathrm{K})\end{array}$ & $\begin{array}{l}\text { Data } \\
\text { Points }\end{array}$ & $\begin{array}{c}\text { Average Absolute } \\
\text { Relative } \\
\text { Deviation (\%) }\end{array}$ & Reference & $\begin{array}{l}\text { Temperature } \\
\text { Range }(\mathrm{K})\end{array}$ & $\begin{array}{l}\text { Data } \\
\text { Points }\end{array}$ & $\begin{array}{l}\text { Average Absolut } \\
\text { Relative } \\
\text { Deviation }(\%)\end{array}$ & Reference \\
\hline \multicolumn{4}{|c|}{$\left[\mathrm{C}_{4} \mathrm{mIm}\right]\left[\mathrm{PF}_{6}\right]$} & \multicolumn{4}{|c|}{$\left[\mathrm{C}_{4} \mathrm{mIm}\right]\left[\mathrm{Tf}_{2} \mathrm{~N}\right]$} \\
\hline 298.1 & 1 & 0.07 & 12 & 298.15 & 1 & 0.09 & 69 \\
\hline 298.15 & 1 & 0.05 & 49 & $293.15-333.15$ & 4 & 0.09 & 125 \\
\hline 298.15 & 1 & 0.04 & 50 & \multicolumn{4}{|c|}{$\left[\mathrm{C}_{6} \mathrm{mIm}\right]\left[\mathrm{Tf}_{2} \mathrm{~N}\right]$} \\
\hline $283.15-343.15$ & 13 & 0.03 & 36 & $293.15-333.15$ & 4 & 0.11 & 125 \\
\hline $293.15-303.15$ & 3 & 0.04 & 51 & \multicolumn{4}{|c|}{$\left[\mathrm{C}_{8} \mathrm{mIm}\right]\left[\mathrm{Tf}_{2} \mathrm{~N}\right]$} \\
\hline 298.15 & 1 & 0.04 & 52 & 298.15 & 1 & 0.35 & 65 \\
\hline 298.15 & 1 & 0.04 & 53 & $293.15-333.15$ & 4 & 0.21 & 125 \\
\hline $293.15-303.15$ & 3 & 0.04 & 54 & \multicolumn{4}{|c|}{$\left[\mathrm{C}_{10} \mathrm{mIm}\right]\left[\mathrm{Tf}_{2} \mathrm{~N}\right]$} \\
\hline 298.15 & 1 & 0.04 & 55 & 293.15-333.15 & 4 & 0.31 & 125 \\
\hline $288.15-343.15$ & 12 & 0.05 & 56 & \multicolumn{4}{|c|}{$\left[\mathrm{C}_{1} \mathrm{e} \mathrm{Im}\right]\left[\mathrm{Tf}_{2} \mathrm{~N}\right]$} \\
\hline 298.15 & 1 & 0.08 & 57 & 298.15 & 1 & 0.23 & 69 \\
\hline \multicolumn{4}{|c|}{$\left[\mathrm{C}_{6} \mathrm{mIm}\right]\left[\mathrm{PF}_{6}\right]$} & \multicolumn{4}{|c|}{$\left[\mathrm{C}_{4} \mathrm{e} \mathrm{Im}\right]\left[\mathrm{Tf}_{2} \mathrm{~N}\right]$} \\
\hline $288.15-318.15$ & 7 & 0.11 & 58 & 298.15 & 1 & 0.03 & 69 \\
\hline 298.15 & 1 & 0.12 & 50 & \multicolumn{4}{|c|}{$\left[\mathrm{C}_{2} \mathrm{mIm}\right]\left[\mathrm{CF}_{3} \mathrm{SO}_{3}\right]$} \\
\hline $293.15-303.15$ & 3 & 0.11 & 51 & 298.15 & 1 & 0.11 & 69 \\
\hline 298.15 & 1 & 0.12 & 52 & \multicolumn{4}{|c|}{$\left[\mathrm{C}_{4} \mathrm{mIm}\right]\left[\mathrm{CF}_{3} \mathrm{SO}_{3}\right]$} \\
\hline $293.15-303.15$ & 3 & 0.11 & 54 & 298.15 & 1 & 0.01 & 69 \\
\hline \multicolumn{4}{|c|}{$\left[\mathrm{C}_{8} \mathrm{mim}\right]\left[\mathrm{PF}_{6}\right]$} & $293.15-333.15$ & 4 & 0.10 & 125 \\
\hline 298.1 & 1 & 0.03 & 12 & \multicolumn{4}{|c|}{$\left[\mathrm{C}_{1} \mathrm{e} \mathrm{Im}\right]\left[\mathrm{CF}_{3} \mathrm{SO}_{3}\right]$} \\
\hline 298.1 & 1 & 0.04 & 50 & 298.15 & 1 & 0.14 & 69 \\
\hline $283.15-343.15$ & 13 & 0.05 & 36 & \multicolumn{4}{|c|}{$\left[\mathrm{C}_{4} \mathrm{e} I m\right]\left[\mathrm{CF}_{3} \mathrm{SO}_{3}\right]$} \\
\hline $293.15-303.15$ & 3 & 0.04 & 51 & 298.15 & 1 & 0.00 & 69 \\
\hline 298.15 & 1 & 0.04 & 52 & \multicolumn{4}{|c|}{$\left[\mathrm{C}_{1} \mathrm{mIm}\right]\left[\mathrm{MeSO}_{4}\right]$} \\
\hline $293.15-303.15$ & 3 & 0.04 & 54 & $283.15-343.15$ & 13 & 0.43 & 70 \\
\hline \multicolumn{4}{|c|}{$\left[\mathrm{C}_{4} \mathrm{mim}\right]\left[\mathrm{BF}_{4}\right]$} & 293.15-303.15 & 3 & 0.37 & 51 \\
\hline $298.3-323.0$ & 6 & 0.26 & 59 & 298.15 & 1 & 0.38 & 52 \\
\hline 298.15 & 1 & 0.16 & 60 & 298.15 & 1 & 0.38 & 53 \\
\hline $288.15-343.15$ & 12 & 0.03 & 56 & \multicolumn{4}{|c|}{$\left[\mathrm{C}_{4} \mathrm{mIm}\right]\left[\mathrm{MeSO}_{4}\right]$} \\
\hline 298.15 & 1 & 0.16 & 61 & $283.15-343.15$ & 13 & 0.40 & 37 \\
\hline 298.15 & 1 & 0.17 & 41 & $293.15-303.15$ & 3 & 0.48 & 51 \\
\hline \multicolumn{4}{|c|}{$\left[\mathrm{C}_{6} \mathrm{mim}\right]\left[\mathrm{BF}_{4}\right]$} & 298.15 & 1 & 0.48 & 61 \\
\hline 298 & 1 & 0.16 & 62 & \multicolumn{4}{|c|}{$\left[\mathrm{C}_{2} \mathrm{mIm}\right]\left[\mathrm{EtSO}_{4}\right]$} \\
\hline & & ]$\left[\mathrm{BF}_{4}\right]$ & & $288.15-343.15$ & 12 & 0.19 & 23 \\
\hline 298.15 & 1 & 0.14 & 63 & 298.15 & 1 & 0.30 & 22 \\
\hline 298.15 & 1 & 0.08 & 64 & 298.15 & 1 & 0.27 & 32 \\
\hline 298.15 & 1 & 0.08 & 65 & 298.15 & 1 & 0.30 & 30 \\
\hline $288.15-343.15$ & 12 & 0.05 & 56 & & & $\mathrm{n}][\mathrm{Cl}]$ & \\
\hline 298.15 & 1 & 0.02 & 66 & 298.15 & 1 & 0.47 & 12 \\
\hline 298.15 & 1 & 0.14 & 67 & $298.15-343.15$ & 10 & 0.61 & 24 \\
\hline $283.15-363.15$ & 17 & 0.02 & 68 & & & $\mathrm{n}][\mathrm{Cl}]$ & \\
\hline & {$\left[\mathrm{C}_{4}\right.$} & $\mathrm{n}]\left[\mathrm{BF}_{4}\right]$ & & 298.15 & 1 & 0.61 & 12 \\
\hline 298.15 & 1 & 0.00 & 41 & 298.15 & 1 & 0.47 & 71 \\
\hline & & {$\left[\mathrm{Tf}_{2} \mathrm{~N}\right]$} & & 298.15 & 1 & 0.55 & 72 \\
\hline 298.15 & 1 & 0.39 & 69 & $298.15-343.15$ & 10 & 0.30 & 24 \\
\hline & & {$\left[\mathrm{Tf}_{2} \mathrm{~N}\right]$} & & 298.15 & 1 & 0.24 & 73 \\
\hline 298.15 & 1 & 0.25 & 69 & 298.15 & 1 & 0.24 & 74 \\
\hline $293.15-333.15$ & 4 & 0.24 & 125 & & & & \\
\hline Total & & & & $283.15-363.15$ & 245 & 0.18 & \\
\hline
\end{tabular}

having $\mathrm{PF}_{6}, \mathrm{BF}_{4}, \mathrm{Tf}_{2} \mathrm{~N}, \mathrm{EtSO}_{4}, \mathrm{CF}_{3} \mathrm{SO}_{3}$, or $\mathrm{Cl}$ as anions, are in very good agreement with the corresponding experimental thermal conductivity $\left(\kappa_{\mathrm{exp}}\right)$; where $\kappa_{\mathrm{cal}}=(0.9991 \pm$ $0.0017) \cdot \kappa_{\exp }\left(R^{2}=0.9997\right.$ at $95 \%$ level of confidence). Relative deviations between the calculated and experimental thermal conductivity data as a function of experimental thermal conductivity for all data points used in the current study are shown in Figure 5. For 107 data points of 16 ILs available in literature, ${ }^{42-45}$ the overall RD is $1.06 \%$ with a maximum deviation of the order of $3.5 \%$. From these $55.2 \%$ of the estimated thermal conductivities were within relative deviation of $0.00-1.00 \%, 25.2 \%$ within $1.001-2.00 \%$, with only $19.6 \%$ of the estimated thermal conductivities showing a deviation larger than $2 \%$. The maximum relative deviation of $3.49 \%$ was observed for $\left[\mathrm{C}_{2} \mathrm{mim}\right][\mathrm{BF} 4]$ (1-ethyl-3methylimidazolium tetrafluoroborate) and $\left[\mathrm{C}_{4} \mathrm{mim}\right][\mathrm{BF} 4]$ (1-butyl-3-methylimidazolium tetrafluoroborate) at 300 $\mathrm{K} .{ }^{43}$ The thermal conductivity of the ILs is similar to what is observed for organic molecular liquids and much lower than that for pure water. Small amounts of impurities, such as water and chloride, in the IL sample do not seem to have a significant effect on the thermal conductivity; however, the thermal conductivity seems to increase with the amount of impurities. ${ }^{45}$ For ILs having an imidazolium based cation, the thermal conductivity increases with the anion following the trend: $\left[\mathrm{Tf}_{2} \mathrm{~N}\right]<\left[\mathrm{CF}_{3} \mathrm{SO}_{3}\right] \leq\left[\mathrm{PF}_{6}\right]<\left[\mathrm{EtSO}_{4}\right]<\left[\mathrm{BF}_{4}\right]$. 
Table 8. Group Contributions Parameters $a_{i}, n_{\mathrm{D}}$ and $b_{i}, n_{\mathrm{D}}$ in Eq. 16 for Temperature Range 283.15-363.15 K

\begin{tabular}{lll}
\hline \multicolumn{1}{c}{ Species } & $a_{i}, n_{\mathrm{D}}$ & $b_{i}, n_{\mathrm{D}}\left(\mathrm{K}^{-1}\right)$ \\
\hline Cations & & \\
$\quad$ 1,3-dimethylimidazolium (+) & 1.4436 & $2.268 \times 10^{-4}$ \\
Anions & & \\
$\mathrm{PF}_{6}^{-}$ & 0.0330 & $2.821 \times 10^{-5}$ \\
$\mathrm{BF}_{4}^{-}$ & 0.0427 & $2.835 \times 10^{-5}$ \\
$\mathrm{Tf}_{2} \mathrm{~N}^{-}$ & 0.0628 & $7.506 \times 10^{-5}$ \\
$\mathrm{CF}_{3} \mathrm{SO}_{3}^{-}$ & 0.0783 & $8.653 \times 10^{-5}$ \\
$\mathrm{MeSO}_{4}^{-}$ & 0.1314 & $1.016 \times 10^{-4}$ \\
$\mathrm{EtSO}_{4}^{-}$ & 0.1667 & $1.749 \times 10^{-4}$ \\
$\mathrm{Cl}^{-}$ & 0.1247 & $2.836 \times 10^{-5}$ \\
$\mathrm{Groups}^{\mathrm{CH}}$ & & \\
$\mathrm{CH}_{3}$ & 0.0045 & $4.587 \times 10^{-6}$ \\
& 0.0353 & $7.330 \times 10^{-5}$ \\
\hline
\end{tabular}

The thermal conductivity also increases somewhat with the increase of alkyl chain length on imidazolium cation.

\section{Refractive index}

Refractive index $\left(n_{\mathrm{D}}\right)$ is a fundamental physical property and it is used to testing a material, confirm its purity, or to calculate the concentration of a mixture. It is important for optics related research fields. It is also related to other properties such as dielectric constant, density, and surface tension through thermodynamic equations.

Experimental refractive index data available in the open literature are reported in Table 7 . It was possible to find 245 data points for 24 imidazolium based ILs having $\mathrm{PF}_{6}, \mathrm{BF}_{4}, \mathrm{Tf}_{2} \mathrm{~N}, \mathrm{MeSO}_{4}, \mathrm{EtSO}_{4}, \mathrm{CF}_{3} \mathrm{SO}_{3}$, or $\mathrm{Cl}$ as anions, covering a wide range of temperature, 283.15$363.15 \mathrm{~K},{ }^{12,19,22,23,24,30,32,36,37,41,49-74}$ that were used in this study. For the studied ILs in the temperature range available, it was observed that the experimental refractive index of IL linearly decreases with temperature, and could be fitted with a linear correlation of the form:

$$
n_{\mathrm{D}}=A_{n_{\mathrm{D}}}-B_{n_{\mathrm{D}}} T
$$

where $A_{n_{\mathrm{D}}}$ and $B_{n_{\mathrm{D}}}$ can be obtained from a group contribution approach as

$$
A_{n_{\mathrm{D}}}=\sum_{i=1}^{k} n_{i} a_{i, n_{\mathrm{D}}} \quad B_{n_{\mathrm{D}}}=\sum_{i=1}^{k} n_{i} b_{i, n_{\mathrm{D}}}
$$

where $n_{i}$ is the number of groups of type $i$ and $k$ is the total number of different of groups in the molecule, and the parameters $a_{i}, n_{\mathrm{D}}$, and $b_{i}, n_{\mathrm{D}}$ here estimated are reported in Table 8.

The parameter estimation followed the approach previously described for the other properties by minimization of the objective function below

$$
\text { O.F. }=\sum_{i=1}^{N_{p}}\left[\left(\left(A_{n_{\mathrm{D}}}-B_{n_{\mathrm{D}}} T\right)-n_{D_{\exp }}\right)^{2}\right]_{i}
$$

The calculated refractive index $\left(n_{\mathrm{D}, \mathrm{cal}}\right)$ from Eqs. 15 and 16 using with group contribution parameters $A_{\mathrm{i}}, \mathrm{n}_{\mathrm{D}}$ and $b_{\mathrm{i}}$ from Table 8 for imidazolium based ILs having $\mathrm{PF}_{6}, \mathrm{BF}_{4}, \mathrm{Tf}_{2} \mathrm{~N}$, $\mathrm{MeSO}_{4}, \mathrm{EtSO}_{4}, \mathrm{CF}_{3} \mathrm{SO}_{3}$, or $\mathrm{Cl}$ as anions, are in excellent agreement with the corresponding experimental refractive index
$\left(n_{\mathrm{D}, \exp }\right) ;$ where $n_{\mathrm{D}, \mathrm{cal}}=(0.9999 \pm 0.0002) \cdot n_{\mathrm{D}, \exp }\left(R^{2}=0.9977\right.$ at $95 \%$ level of confidence). Relative deviations between the calculated and experimental refractive index data as a function of experimental refractive index for all data points used in the current study are shown in Figure 6. For 245 data points of 24 ILs available in literature, the overall RD is $0.18 \%$ with a maximum deviation of the order of $0.6 \%$. From these about $47.8 \%$ of the estimated refractive indices were within a relative deviation of $0.00-0.10 \%, 45.7 \%$ within $0.101-0.50 \%$, and only $6.5 \%$ of the estimated refractive indices having larger than $0.5 \%$ deviation. The maximum relative deviation is $0.61 \%$ observed for $\left[\mathrm{C}_{6} \mathrm{mim}\right][\mathrm{Cl}]$ (1-hexyl-3-methylimidazolium chloride). ${ }^{24}$ The results indicate that the refractive index of studied ILs is weakly dependent on temperature and it slightly decreases with temperature. The refractive index of all studied ILs is higher than what is observed for pure water. Water present in IL sample as an impurity has no significant effect on the refractive index; however, from the refractive index data of aqueous solutions of ILs, ${ }^{23,41,120}$ it is clear that the refractive index decreases with increasing amount of water. For ILs having imidazolium based cation, refractive index is increased with anion follows the trend: $\left[\mathrm{PF}_{6}\right]<\left[\mathrm{BF}_{4}\right]<\left[\mathrm{Tf}_{2} \mathrm{~N}\right]<\left[\mathrm{CF}_{3} \mathrm{SO}_{3}\right]<$ $\left[\mathrm{MeSO}_{4}\right]<\left[\mathrm{EtSO}_{4}\right]<[\mathrm{Cl}]$; and it increases a little with the increase of alkyl chain length on the imidazolium cation. The low deviations observed in calculated refractive indices for a wide range of imidazolium based ILs shows that the group contribution method here developed can predict refractive index of new ionic liquids in wide ranges of temperatures and, as data for new groups of cations and anions became available, can be easily extended to a larger range of ionic liquids.

\section{Isobaric expansivity}

Thermal expansion of a material must be considered in engineering applications where changes in dimension or density due to temperature are expected. It is an important property to be considered while developing the ILs as heat transfer fluids or for heat storage applications ${ }^{42,43,121}$ or, as recently suggested, for IL based liquid-in-glass thermometers. ${ }^{122}$

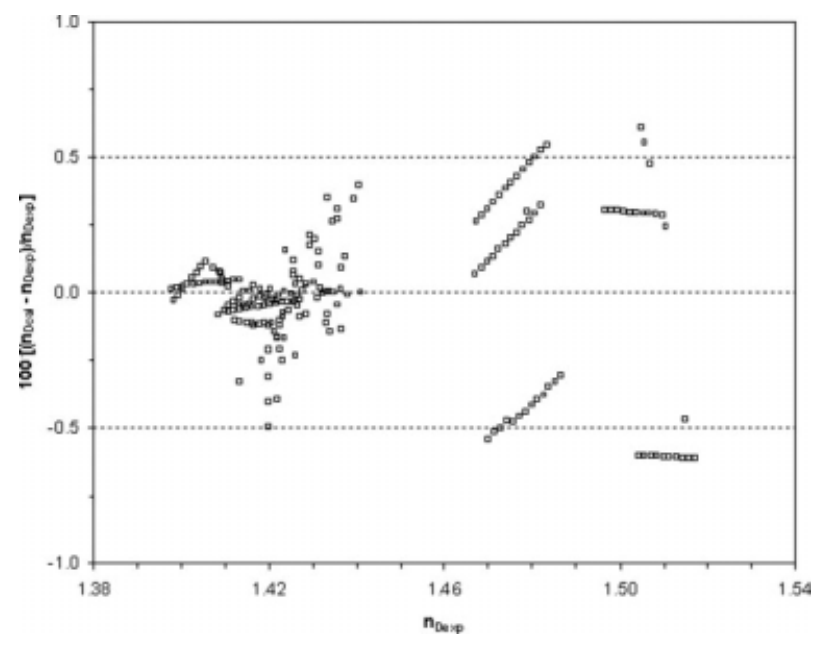

Figure 6. Relative deviations between the calculated and experimental refractive index as function of experimental refractive index for imidazolium-based ionic liquids in the current study. 
Table 9. Prediction of Isobaric Expansivity of Imidazolium-, Pyridinium-, Pyrrolidinium-, Piperidinium-, Phosphonium-, and Ammonium-Based Ionic Liquids at 298.15 K and 0.1 MPa

\begin{tabular}{|c|c|c|c|c|c|}
\hline $10^{4} \alpha_{\text {Pexp }}\left(\mathrm{K}^{-1}\right)$ & Relative Deviation $(\%)$ & Reference & $10^{4} \alpha_{\text {Pexp }}\left(\mathrm{K}^{-1}\right)$ & Relative Deviation (\%) & Reference \\
\hline & {$\left[\mathrm{C}_{4} \mathrm{mIm}\right]\left[\mathrm{PF}_{6}\right]$} & & & {$\left[\mathrm{C}_{4} \mathrm{mIm}\right]\left[\mathrm{C}(\mathrm{CN})_{3}\right]$} & \\
\hline 6.00 & 2.83 & 29 & 7.41 & 0.00 & 94 \\
\hline 6.06 & 1.79 & 75 & & {$\left[\mathrm{C}_{6} \mathrm{mIm}\right][\mathrm{Cl}]$} & \\
\hline 6.11 & 1.01 & 76 & 5.50 & -1.24 & 24 \\
\hline 6.16 & 0.20 & 77 & & {$\left[\mathrm{C}_{8} \mathrm{mIm}\right][\mathrm{Cl}]$} & \\
\hline 6.16 & 0.18 & 81 & 5.72 & -3.67 & 24 \\
\hline 6.17 & 0.01 & 78 & 5.72 & -3.67 & 73 \\
\hline 6.20 & -0.40 & 79 & & {$\left[\mathrm{C}_{1} \mathrm{mIm}\right]\left[\mathrm{MeSO}_{4}\right]$} & \\
\hline 6.23 & -0.91 & 36 & 5.42 & 0.89 & 54 \\
\hline 6.24 & -1.15 & 56 & 5.44 & 0.67 & 70 \\
\hline 6.31 & -2.13 & 82 & 5.76 & -4.95 & 95 \\
\hline \multirow[t]{2}{*}{6.10} & 1.19 & 34 & & {$\left[\mathrm{C}_{4} \mathrm{mIm}\right]\left[\mathrm{MeSO}_{4}\right]$} & \\
\hline & {$\left[\mathrm{C}_{6} \mathrm{mIm}\right]\left[\mathrm{PF}_{6}\right]$} & & 5.48 & 2.00 & 84 \\
\hline 6.18 & 1.19 & 33 & 5.61 & -0.22 & 37 \\
\hline 6.36 & -1.74 & 58 & 5.61 & -0.27 & 51 \\
\hline \multirow[t]{2}{*}{6.20} & 0.87 & 34 & 5.61 & -0.34 & 96 \\
\hline & {$\left[\mathrm{C}_{8} \mathrm{mIm}\right]\left[\mathrm{PF}_{6}\right]$} & & & {$\left[\mathrm{C}_{2} \mathrm{mIm}\right]\left[\mathrm{EtSO}_{4}\right]$} & \\
\hline 6.20 & 2.11 & 25 & 5.42 & 0.97 & 98 \\
\hline 6.33 & 0.04 & 36 & 5.47 & 0.00 & 23 \\
\hline \multirow[t]{2}{*}{6.20} & 2.17 & 34 & 5.49 & -0.36 & 27 \\
\hline & {$\left[\mathrm{C}_{4} \mathrm{mmIm}\right]\left[\mathrm{PF}_{6}\right]$} & & 5.61 & -2.44 & 89 \\
\hline \multirow[t]{2}{*}{7.11} & -0.43 & 81 & & {$\left[\mathrm{C}_{4} \mathrm{mIm}\right]\left[\mathrm{CF}_{3} \mathrm{COO}\right]$} & \\
\hline & {$\left[\mathrm{C}_{2} \mathrm{mIm}\right]\left[\mathrm{BF}_{4}\right]$} & & 6.32 & -0.20 & 28 \\
\hline 5.76 & 1.56 & 82 & & {$\left[\mathrm{C}_{4} \mathrm{mIm}\right]\left[\mathrm{Pf}_{2} \mathrm{~N}\right]$} & \\
\hline 5.64 & 3.77 & 83 & 6.68 & -0.23 & 28 \\
\hline \multirow[t]{2}{*}{6.18} & -5.23 & 84 & & {$\left[\mathrm{C}_{1} \mathrm{mIm}\right]\left[\left(\mathrm{CH}_{3}\right)_{2} \mathrm{PO}_{4}\right]$} & \\
\hline & {$\left[\mathrm{C}_{4} \mathrm{mIm}\right]\left[\mathrm{BF}_{4}\right]$} & & 5.16 & 0.83 & 95 \\
\hline 5.68 & 4.44 & 84 & & {$\left[\mathrm{C}_{1} \mathrm{mIm}\right]\left[\mathrm{CH}_{3} \mathrm{OC}_{2} \mathrm{H}_{4} \mathrm{SO}_{4}\right]$} & \\
\hline 5.90 & 0.63 & 85 & 5.27 & -0.53 & 95 \\
\hline 5.91 & 0.49 & 86 & & {$\left[\mathrm{C}_{4} \mathrm{mIm}\right]\left[\mathrm{AlCl}_{4}\right]$} & \\
\hline 5.94 & -0.02 & 60 & 4.48 & -0.12 & 98 \\
\hline 5.94 & -0.09 & 75 & & {$\left[\mathrm{C}_{4} \mathrm{mIm}\right]\left[\mathrm{FeCl}_{4}\right]$} & \\
\hline 5.96 & -0.36 & 34 & 4.74 & 0.01 & 99 \\
\hline 5.96 & -0.48 & 38 & & {$\left[\mathrm{C}_{4} \mathrm{mIm}\right]\left[\mathrm{ZnCl}_{3}\right]$} & \\
\hline 5.99 & -0.91 & 87 & 5.36 & -0.04 & 100 \\
\hline 6.02 & -1.42 & 77 & & {$\left[\mathrm{C}_{2} \mathrm{mIm}\right]\left[\mathrm{GaCl}_{4}\right]$} & \\
\hline 6.01 & -1.22 & 28 & 5.82 & -0.01 & 101 \\
\hline 6.05 & -1.91 & 56 & & {$\left[\mathrm{C}_{4} \mathrm{mIm}\right]\left[\mathrm{GaCl}_{4}\right]$} & \\
\hline 6.18 & -4.00 & 29 & 5.98 & -1.33 & 102 \\
\hline \multirow[t]{2}{*}{5.90} & 0.59 & 34 & & {$\left[\mathrm{C}_{2} \mathrm{mIm}\right]\left[\mathrm{InCl}_{4}\right]$} & \\
\hline & {$\left[\mathrm{C}_{6} \mathrm{mIm}\right]\left[\mathrm{BF}_{4}\right]$} & & 6.53 & -0.76 & 103 \\
\hline 6.13 & -1.79 & 38 & & {$\left[\mathrm{C}_{4} \mathrm{mIm}\right]\left[\mathrm{InCl}_{4}\right]$} & \\
\hline \multirow{2}{*}{6.30} & -4.44 & 84 & 6.50 & -0.95 & 104 \\
\hline & {$\left[\mathrm{C}_{8} \mathrm{mIm}\right]\left[\mathrm{BF}_{4}\right]$} & & & {$\left[\mathrm{C}_{2} \mathrm{Py}\right]\left[\mathrm{Tf}_{2} \mathrm{~N}\right]$} & \\
\hline 6.20 & -1.60 & 38 & 6.55 & -6.77 & 95 \\
\hline 6.23 & -2.21 & 25 & & {$\left[\mathrm{C}_{4} \mathrm{Py}\right]\left[\mathrm{Tf}_{2} \mathrm{~N}\right]$} & \\
\hline 6.28 & -2.93 & 56 & 6.36 & $\begin{array}{r}{[-7.79} \\
-2.79\end{array}$ & 28 \\
\hline \multirow[t]{2}{*}{6.20} & -1.66 & 34 & & {$\left[\mathrm{C}_{3} \mathrm{mPy}\right]\left[\mathrm{Tf}_{2} \mathrm{~N}\right]$} & \\
\hline & {$\left[\mathrm{C}_{1} \mathrm{mIm}\right]\left[\mathrm{Tf}_{2} \mathrm{~N}\right]$} & & 7.22 & -2.38 & 105 \\
\hline 6.67 & -0.31 & 88 & & {$\left[\mathrm{C}_{4} \mathrm{Py}\right]\left[\mathrm{BF}_{4}\right]$} & \\
\hline \multirow{2}{*}{6.57} & 1.18 & 28 & 5.01 & 6.77 & 106 \\
\hline & {$\left[\mathrm{C}_{2} \mathrm{mIm}\right]\left[\mathrm{Tf}_{2} \mathrm{~N}\right]$} & & & {$\left[\mathrm{C}_{4} \mathrm{mPy}\right]\left[\mathrm{BF}_{4}\right]$} & \\
\hline 6.44 & 3.81 & 28 & 5.91 & 5.84 & 107 \\
\hline 6.57 & 1.78 & 21 & 6.37 & -1.79 & 108 \\
\hline 6.62 & 1.02 & 89 & & {$\left[\mathrm{C}_{3} \mathrm{mPyr}\right]\left[\mathrm{Tf}_{2} \mathrm{~N}\right]$} & \\
\hline 6.61 & 1.25 & 77 & 7.03 & -6.49 & 105 \\
\hline \multirow[t]{2}{*}{6.70} & -0.23 & 88 & & {$\left[\mathrm{C}_{4} \mathrm{mPyr}\right]\left[\mathrm{Tf}_{2} \mathrm{~N}\right]$} & \\
\hline & {$\left[\mathrm{C}_{4} \mathrm{mIm}\right]\left[\mathrm{Tf}_{2} \mathrm{~N}\right]$} & & 6.21 & 6.50 & 109 \\
\hline 6.53 & 3.67 & 21 & 6.51 & 1.53 & 28 \\
\hline 6.60 & 2.55 & 77 & 7.04 & -6.05 & 105 \\
\hline 6.64 & 1.92 & 77 & & {$\left[\mathrm{C}_{3} \mathrm{mPip}\left[\mathrm{Tf}_{2} \mathrm{~N}\right]\right.$} & \\
\hline 6.66 & 1.68 & 58 & 7.17 & 2.03 & 105 \\
\hline 6.70 & 1.02 & 34 & & {$[\mathrm{THTDPh}]\left[\mathrm{Tf}_{2} \mathrm{~N}\right]$} & \\
\hline 6.68 & 1.38 & 80 & 7.44 & 3.91 & 110 \\
\hline \multirow[t]{2}{*}{6.73} & 0.56 & 88 & & [THTDPh][Cl] & \\
\hline & {$\left[\mathrm{C}_{6} \mathrm{mIm}\right]\left[\mathrm{Tf}_{2} \mathrm{~N}\right]$} & & 6.63 & -4.79 & 112 \\
\hline 6.53 & 4.92 & 40 & 5.96 & 5.97 & 110 \\
\hline
\end{tabular}


Table 9. (Continued)

\begin{tabular}{|c|c|c|c|c|c|}
\hline $10^{4} \alpha_{\mathrm{Pexp}}\left(\mathrm{K}^{-1}\right)$ & Relative Deviation (\%) & Reference & $10^{4} \alpha_{\operatorname{Pexp}}\left(\mathrm{K}^{-1}\right)$ & Relative Deviation (\%) & Reference \\
\hline 6.54 & 4.71 & 90 & & {$[\mathrm{THTDPh}]\left[\mathrm{CH}_{3} \mathrm{COO}\right]$} & \\
\hline 6.60 & 3.72 & 91 & 6.77 & -0.31 & 110 \\
\hline 6.65 & 2.97 & 35 & & {$[\mathrm{THTDPh}]\left[\mathrm{N}(\mathrm{CN})_{2}\right]$} & \\
\hline & {$\left[\mathrm{C}_{8} \mathrm{mIm}\right]\left[\mathrm{Tf}_{2} \mathrm{~N}\right]$} & & 5.69 & -0.62 & 111 \\
\hline 6.73 & 2.97 & 92 & & {$[\mathrm{Am}(4) 111]\left[\mathrm{Tf}_{2} \mathrm{~N}\right]$} & \\
\hline 608 & {$\left[\mathrm{C}_{2} \mathrm{mIm}\right]\left[\mathrm{CF}_{3} \mathrm{SO}_{3}\right]$} & 03 & 6.05 & $\begin{array}{c}-7.10 \\
\end{array}$ & 111 \\
\hline $\begin{array}{l}6.08 \\
6.08\end{array}$ & $\begin{array}{r}-0.07 \\
0.06\end{array}$ & $\begin{array}{l}93 \\
27\end{array}$ & 592 & $\begin{array}{c}{[\mathrm{Am}(6) 111]\left[\mathrm{Tf}_{2} \mathrm{~N}\right]} \\
-369\end{array}$ & 111 \\
\hline & {$\left[\mathrm{C}_{4} \mathrm{mIm}\right]\left[\mathrm{CF}_{3} \mathrm{SO}_{3}\right]$} & & & {$[\mathrm{Am}(10) 111]\left[\mathrm{Tf}_{2} \mathrm{~N}\right]$} & \\
\hline 6.16 & $\begin{array}{c}-0.04 \\
{[\mathrm{Am}(6) 222]\left[\mathrm{Tf}_{2} \mathrm{~N}\right]}\end{array}$ & 28 & 6.03 & $\begin{array}{c}-2.76 \\
{[\mathrm{Am}(1) 888]\left[\mathrm{Tf}_{2} \mathrm{~N}\right]}\end{array}$ & 111 \\
\hline 5.79 & 0.58 & 111 & 5.93 & 7.09 & 111 \\
\hline
\end{tabular}

The isobaric expansivity $\left(\alpha_{\mathrm{P}}\right)$ is defined as

$$
\alpha_{\mathrm{P}}=\frac{1}{V_{\mathrm{m}}}\left(\frac{\partial V_{\mathrm{m}}}{\partial T}\right)_{P}=-\frac{1}{\rho}\left(\frac{\partial \rho}{\partial T}\right)_{P}=-\left(\frac{\partial \ln \rho}{\partial T}\right)_{P}
$$

where $V_{\mathrm{m}}$ is molar volume, $\rho$ is density and $T$ is temperature at constant pressure $P$.

Experimental isobaric expansivity data directly available in literature or calculated using experimental density data using Eq. 18 at $298.15 \mathrm{~K}$ are reported in Table 9. 109 data points for 49 ILs based on imidazolium-, pyridinium-, pyrrolidinium, piperidinium-, phosphonium-, and ammonium cations with 19 different anions, at $298.15 \mathrm{~K}$ and $0.1 \mathrm{MPa},{ }^{21,23-25,27-29,33-38,40,51,54,56,58,60,70,74,76-107,106-111}$ were used in this study. In spite of the wide range of ILs investigated, the isobaric expansivities observed fall in a narrow range of values $\left(4.48 \times 10^{-4}\right.$ to $\left.7.44 \times 10^{-4} \mathrm{~K}^{-1}\right)$ at $298.15 \mathrm{~K}$. As discussed previously ${ }^{4}$ the precision to which this property is currently known precludes any study of its temperature dependency as this is inferior to the experimental uncertainty. For this reason the isobaric expansivity will be here correlated at the temperature of $298.15 \mathrm{~K}$ and atmospheric pressure by a group contribution approach.

$$
\alpha_{\mathrm{P}}=A_{\alpha_{\mathrm{P}}}=\sum_{i=1}^{k} n_{i} a_{i, \alpha_{\mathrm{P}}}
$$

where $n_{i}$ is the number of groups of type $i$ and $k$ is the total number of different groups in the molecule, and the parameters $a_{\mathrm{i}, \alpha \mathrm{P}}$ here estimated for are presented in Table 10 .

The parameter estimation was carried by the minimization of the objective function below

$$
\text { O.F. }=\sum_{i=1}^{N_{p}}\left[\left(A_{\alpha_{\mathrm{P}}}-\alpha_{\mathrm{P} \exp }\right)^{2}\right]_{i}
$$

For the studied ILs, the calculated isobaric expansivity $\left(\alpha_{\mathrm{P}, \mathrm{cal}}\right)$, using Eq. 19 and group contribution parameters $a_{\mathrm{i}}, \alpha_{\mathrm{P}}$ reported in Table 10, are in good agreement with the corresponding experimental isobaric expansivity $\left(\alpha_{\mathrm{P}, \exp }\right)$ data; where $\alpha_{\mathrm{P}, \text { cal }}=$ $(1.0007 \pm 0.0027) \cdot \alpha_{\mathrm{P}, \exp }\left(R^{2}=0.9992\right.$ at $95 \%$ level of confidence). Relative deviations between the calculated and experimental isobaric expansivity data as a function of experimental isobaric expansivity for all data points used in the current study are shown in Figure 7. For 109 data points of 49 ILs available in literature, the overall RD is $1.98 \%$ with a maximum deviation of the order of $7 \%$. From these about $40.4 \%$ of the estimated refractive indices were within relative deviation of $0.00-1.00 \%, 36.7 \%$ within $1.001-3.00 \%, 13.8 \%$ within $3.001-5.00 \%$, and only $9.2 \%$ of the estimated isobaric expansivities having larger than $5 \%$ deviation. The maximum relative deviation is $7.10 \%$ observed for [THTDPh] $\left[\mathrm{N}(\mathrm{CN})_{2}\right]$

\begin{tabular}{|c|c|c|c|}
\hline Species & $a_{i, \alpha_{\mathrm{p}}}\left(\mathrm{K}^{-1}\right)$ & Species & $a_{i, \alpha_{\mathrm{p}}}\left(\mathrm{K}^{-1}\right)$ \\
\hline Cations & & Anions & \\
\hline 1,3-dimethylimidazolium $(+)$ & $3.498 \times 10^{-4}$ & $\mathrm{Cl}^{-}$ & $1.733 \times 10^{-4}$ \\
\hline 1-methylpyridinium $(+)$ & $2.916 \times 10^{-4}$ & $\mathrm{CH}_{3} \mathrm{COO}^{-}$ & $2.170 \times 10^{-4}$ \\
\hline 1,1-dimethylpyrrolidinium $(+)$ & $3.342 \times 10^{-4}$ & $\mathrm{CF}_{3} \mathrm{COO}^{-}$ & $2.683 \times 10^{-4}$ \\
\hline 1,1-dimethylpiperidinium $(+)$ & $4.085 \times 10^{-4}$ & $\mathrm{MeSO}_{4}^{-}$ & $1.975 \times 10^{-4}$ \\
\hline Trihexylteradecyl phosphonium (+) & $4.583 \times 10^{-4}$ & $\mathrm{EtSO}_{4}^{-}$ & $1.935 \times 10^{-4}$ \\
\hline Tetramethyl ammonium $(+)$ & $2.350 \times 10^{-4}$ & $\left(\mathrm{CH}_{3}\right)_{2} \mathrm{PO}_{4}^{-}$ & $1.701 \times 10^{-4}$ \\
\hline Groups & & $\mathrm{CH}_{3} \mathrm{OC}_{2} \mathrm{H}_{4} \mathrm{SO}_{4}^{-}$ & $1.748 \times 10^{-4}$ \\
\hline $\mathrm{CH}_{2}$ & $4.054 \times 10^{-6}$ & $\mathrm{Pf}_{2} \mathrm{~N}^{-}$ & $3.041 \times 10^{-4}$ \\
\hline $\mathrm{CH}_{3}$ & $9.024 \times 10^{-5}$ & $\mathrm{~N}(\mathrm{CN})_{2}{ }^{-}$ & $1.072 \times 10^{-4}$ \\
\hline Anions & & $\mathrm{AlCl}_{4}^{-}$ & $8.551 \times 10^{-5}$ \\
\hline $\mathrm{PF}_{6}^{-}$ & $2.553 \times 10^{-4}$ & $\mathrm{FeCl}_{4}^{-}$ & $1.120 \times 10^{-4}$ \\
\hline $\mathrm{BF}_{4}^{-}$ & $2.315 \times 10^{-4}$ & $\mathrm{ZnCl}_{3}^{-}$ & $1.738 \times 10^{-4}$ \\
\hline $\mathrm{Tf}_{2} \mathrm{~N}^{-}$ & $3.149 \times 10^{-4}$ & $\mathrm{GaCl}_{4}^{-}$ & $2.281 \times 10^{-4}$ \\
\hline $\mathrm{CF}_{3} \mathrm{SO}_{3}^{-}$ & $2.541 \times 10^{-4}$ & $\mathrm{InCl}_{4}^{-}$ & $2.942 \times 10^{-4}$ \\
\hline $\mathrm{C}(\mathrm{CN})_{3}$ & $3.795 \times 10^{-4}$ & & \\
\hline
\end{tabular}
(trihexyl(tetradecyl)phosphonium dicyanamide). ${ }^{111}$ The re-

Table 10. Group Contributions Parameters $a_{i, \alpha_{\mathrm{p}}}$ in Eq. 19 at 298.15 K and 0.1 MPa 


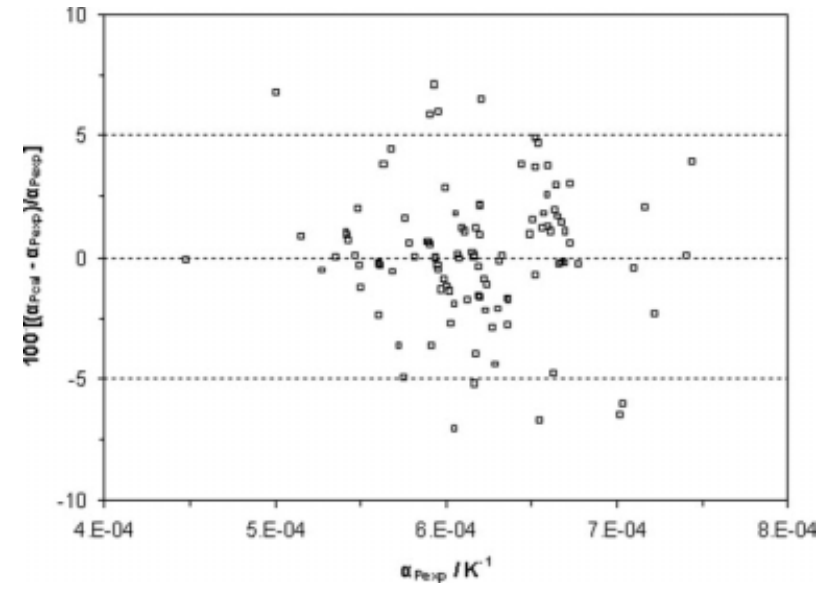

Figure 7. Relative deviations between the calculated and experimental isobaric expansivity as a function of experimental isobaric expansivity for imidazolium-, pyridinium-, pyrrolidinium-, piperidinium-, phosphonium-, and ammonium-based ionic liquids in the current study.

sults indicate that the isobaric expansivity of studied ILs is weakly dependent on anion and it increases poorly with the alkyl chain length on cation.

\section{Isothermal compressibility}

Compressibility is an important factor in thermodynamics, aerodynamics, earth sciences, geotechnical engineering and industrial chemistry. In ionic liquids it is relevant for the design of industrial fluids to be used in pumps or compressors. ${ }^{123}$ The isothermal compressibility $\left(\kappa_{\mathrm{T}}\right)$, is a measure of the relative volume change of a fluid as a response to a pressure change at constant temperature, is directly or indirectly related to several thermodynamic properties, and can be expressed as

$$
k_{\mathrm{T}}=-\frac{1}{V_{\mathrm{m}}}\left(\frac{\partial V_{\mathrm{m}}}{\partial P}\right)_{T}=\frac{1}{\rho}\left(\frac{\partial \rho}{\partial P}\right)_{T}=\left(\frac{\partial \ln \rho}{\partial P}\right)_{T}
$$

Experimental isothermal compressibility data directly available in literature or calculated using experimental density data using Eq. 21 at $298.15 \mathrm{~K}$ are reported in Table 11. In this study 26 data points for 22 ILs based on imidazolium-, pyridinium-, pyrrolidinium, piperidinium-, and phosphonium cations with $\mathrm{PF}_{6}, \mathrm{BF}_{4}, \mathrm{Tf}_{2} \mathrm{~N}, \mathrm{EtSO}_{4}, \mathrm{CF}_{3} \mathrm{SO}_{3}, \mathrm{CH}_{3} \mathrm{COO}, \mathrm{Cl}$ or $\mathrm{C}(\mathrm{CN})_{3}$ as anions, at $298.15 \mathrm{~K}$ and $0.1 \mathrm{MPa}, 75,77,81,86,90,94,105,106,110,124$ were used. As discussed previously ${ }^{4,81}$ the precision to which this property is known preclude any study of its temperature or pressure dependency as this is inferior to the experimental uncertainty. For this reason the isothermal compressibility will be here correlated at the temperature of $298.15 \mathrm{~K}$ and atmospheric pressure by a group contribution approach in the studied range $\left(0.33-0.73 \mathrm{GPa}^{-1}\right)$ of experimental isothermal compressibility data.

$$
\kappa_{\mathrm{T}}=A_{\kappa_{T}}=\sum_{i=1}^{k} n_{i} a_{i, \kappa_{\mathrm{T}}}
$$

where $n_{i}$ is the number of groups of type $i$ and $k$ is the total number of different groups in the molecule, and the parameters $a_{\mathrm{i}}, \kappa_{T}$, here estimated are given in Table 12 .

The parameter estimation was carried by the minimization of the objective function below

$$
\text { O.F. }=\sum_{i=1}^{N_{p}}\left[\left(A_{\kappa_{\mathrm{T}}}-\kappa_{\mathrm{T}_{\mathrm{exp}}}\right)^{2}\right]_{i}
$$

For the studied ILs, the calculated isothermal compressibility $\left(\kappa_{\mathrm{T}, \mathrm{cal}}\right)$, using Eq. 22 and group contribution parameters $a_{\mathrm{i}}, \kappa_{T}$ (Table 12), are in good agreement with the corresponding experimental isothermal compressibility $\left(\kappa_{\mathrm{T}, \mathrm{exp}}\right)$ data; where $\kappa_{\mathrm{T}, \text { cal }}=(1.0055 \pm 0.0064) \cdot \kappa_{\mathrm{T}, \exp }\left(R^{2}=0.9990\right.$ at $95 \%$ level of confidence). Relative deviations between the calculated and experimental isothermal compressibility data as a function of experimental isothermal compressibility for all data points used in the current study are shown in Figure 8. For 26 data points of 22 ILs available in literature, the overall RD is $2.53 \%$ with a maximum deviation of the order of $6.7 \%$ and from these about $46.2 \%$ of the estimated isothermal compressibility data having less than $1 \%$ relative deviation. The maximum relative deviation is $6.67 \%$ observed for $\left[\mathrm{C}_{8} \mathrm{mim}\right][\mathrm{BF} 4]$ (1-octyl-3methylimidazolium tetrafluoroborate) ${ }^{81}$ Imidazolium based ILs are less compressible compare to phosphonium based ILs. However, with the limited amount of experimental data, it is not possible to provide any definitive conclusion on the effect of cation, anion and alkyl chain length on isothermal compressibility of ILs.

Table 11. Prediction of Isothermal Compressibility of Imidazolium-, Pyridinium-, Pyrrolidinium-, Piperidinium-,

\begin{tabular}{|c|c|c|c|}
\hline Ionic Liquid & $\begin{array}{l}\kappa_{\mathrm{Texp}} \\
(\mathrm{GPa})\end{array}$ & $\begin{array}{c}\text { Relative } \\
\text { Deviation }(\%)\end{array}$ & Reference \\
\hline$\left[\mathrm{C}_{4} \mathrm{mIm}\right]\left[\mathrm{PF}_{6}\right]$ & 0.348 & 5.75 & 77 \\
\hline$\left[\mathrm{C}_{6} \mathrm{mIm}\right]\left[\mathrm{PF}_{6}\right]$ & 0.420 & -0.05 & 81 \\
\hline \multirow[t]{2}{*}[\mathrm{C}_{8}\mathrm{mIm}]{$\left[\mathrm{PF}_{6}\right]$} & 0.473 & -0.22 & 81 \\
\hline & 0.469 & 0.58 & 106 \\
\hline$\left[\mathrm{C}_{2} \mathrm{mIm}\right]\left[\mathrm{BF}_{4}\right]$ & 0.331 & -6.47 & 94 \\
\hline \multirow[t]{3}{*}[\mathrm{C}_{4}\mathrm{mIm}]{$\left[\mathrm{BF}_{4}\right]$} & 0.386 & -6.24 & 75 \\
\hline & 0.386 & -6.25 & 86 \\
\hline & 0.360 & 0.56 & 77 \\
\hline$\left[\mathrm{C}_{8} \mathrm{mIm}\right]\left[\mathrm{BF}_{4}\right]$ & 0.437 & 6.67 & 81 \\
\hline$\left[\mathrm{C}_{2} \mathrm{mIm}\right]\left[\mathrm{Tf}_{2} \mathrm{~N}\right]$ & 0.469 & 0.00 & 94 \\
\hline$\left[\mathrm{C}_{3} \mathrm{mIm}\right]\left[\mathrm{Tf}_{2} \mathrm{~N}\right]$ & 0.517 & -4.22 & 124 \\
\hline \multirow[t]{2}{*}[\mathrm{C}_{4}\mathrm{mIm}]{$\left[\mathrm{Tf}_{2} \mathrm{~N}\right]$} & 0.530 & -1.63 & 90 \\
\hline & 0.498 & 4.62 & 76 \\
\hline$\left[\mathrm{C}_{5} \mathrm{mIm}\right]\left[\mathrm{Tf}_{2} \mathrm{~N}\right]$ & 0.544 & 0.46 & 124 \\
\hline$\left[\mathrm{C}_{6} \mathrm{mIm}\right]\left[\mathrm{Tf}_{2} \mathrm{~N}\right]$ & 0.549 & 4.31 & 90 \\
\hline$\left[\mathrm{C}_{2} \mathrm{mIm}\right]\left[\mathrm{CF}_{3} \mathrm{SO}_{3}\right]$ & 0.435 & -3.24 & 105 \\
\hline$\left[\mathrm{C}_{4} \mathrm{mIm}\right]\left[\mathrm{CF}_{3} \mathrm{SO}_{3}\right]$ & 0.457 & 3.43 & 81 \\
\hline$\left[\mathrm{C}_{4} \mathrm{mIm}\right]\left[\mathrm{C}(\mathrm{CN})_{3}\right]$ & 0.405 & -0.05 & 94 \\
\hline$\left[\mathrm{C}_{2} \mathrm{mIm}\right]\left[\mathrm{EtSO}_{4}\right]$ & 0.733 & 0.00 & 77 \\
\hline$\left[\mathrm{C}_{2} \mathrm{Py}\right]\left[\mathrm{BF}_{4}\right]$ & 0.396 & -1.76 & 106 \\
\hline$\left[\mathrm{C}_{3} \mathrm{mPyr}\right]\left[\mathrm{Tf}_{2} \mathrm{~N}\right]$ & 0.516 & -0.05 & 105 \\
\hline$\left[\mathrm{C}_{4} \mathrm{mPyr}\right]\left[\mathrm{Tf}_{2} \mathrm{~N}\right]$ & 0.524 & 3.36 & 105 \\
\hline$\left[\mathrm{C}_{3} \mathrm{mPip}\left[\mathrm{Tf}_{2} \mathrm{~N}\right]\right.$ & 0.507 & -0.01 & 105 \\
\hline$[\mathrm{THTDPh}]\left[\mathrm{Tf}_{2} \mathrm{~N}\right]$ & 0.601 & 5.71 & 110 \\
\hline [THTDPh][Cl] & 0.573 & 0.10 & 110 \\
\hline$[\mathrm{THTDPh}]\left[\mathrm{CH}_{3} \mathrm{COO}\right]$ & 0.573 & 0.05 & 110 \\
\hline
\end{tabular}
and Phosphonium-Based Ionic Liquids at 298.15 $\mathrm{K}$ and 0.1 MPa 
Table 12. Group Contributions Parameters $a_{i}, \kappa_{\mathrm{T}}$ in Eq. 22 at $298.15 \mathrm{~K}$ and $0.1 \mathrm{MPa}$

\begin{tabular}{lc}
\hline \multicolumn{1}{c}{ Species } & $a_{i}, \kappa_{\mathrm{T}}\left(\mathrm{GPa}^{-1}\right)$ \\
\hline Cations & \\
1,3-dimethylimidazolium (+) & 0.196 \\
1-methylpyridinium (+) & 0.223 \\
1,1-dimethylpyrrolidinium (+) & 0.217 \\
1,1-dimethylpiperidinium (+) & 0.208 \\
Trihexylteradecyl phosphonium(+) & 0.388 \\
Group & \\
CH & 0.026 \\
$\mathrm{Anions}_{2}$ & \\
$\mathrm{PF}_{6}^{-}$ & 0.094 \\
$\mathrm{BF}_{4}^{-}$ & 0.088 \\
$\mathrm{Tf}_{2} \mathrm{~N}^{-}$ & 0.247 \\
$\mathrm{CF}_{3} \mathrm{SO}_{3}^{-}$ & 0.199 \\
$\left.\mathrm{C}_{(-\mathrm{CN}}\right)_{3}$ & 0.131 \\
$\mathrm{Cl}^{-}$ & 0.186 \\
$\mathrm{CH}_{3} \mathrm{COO}^{-}$ & 0.185 \\
$\mathrm{EtSO}_{4}^{-}$ & 0.511 \\
\hline
\end{tabular}

\section{Conclusions}

Group contribution methods for estimating the thermophysical and transport properties of ILs were developed for viscosity, electrical conductivity, thermal conductivity, refractive index, isobaric expansivity and isothermal compressibility. A further correlation for the self-diffusion coefficients based on the Stokes-Einstein relation is also proposed. The parameters of the group contribution methods were determined for imidazolium-, pyridinium-, pyrrolidinium, piperidinium-, phosphonium-, and ammonium-based ionic liquids containing several different anions, and circa 1250 experimental data points were used for this purpose. A comparison between the experimental and correlated values showed that the proposed models describe the experimental data available with absolute relative deviations generally of the same order of the agreement of experimental data by dif-

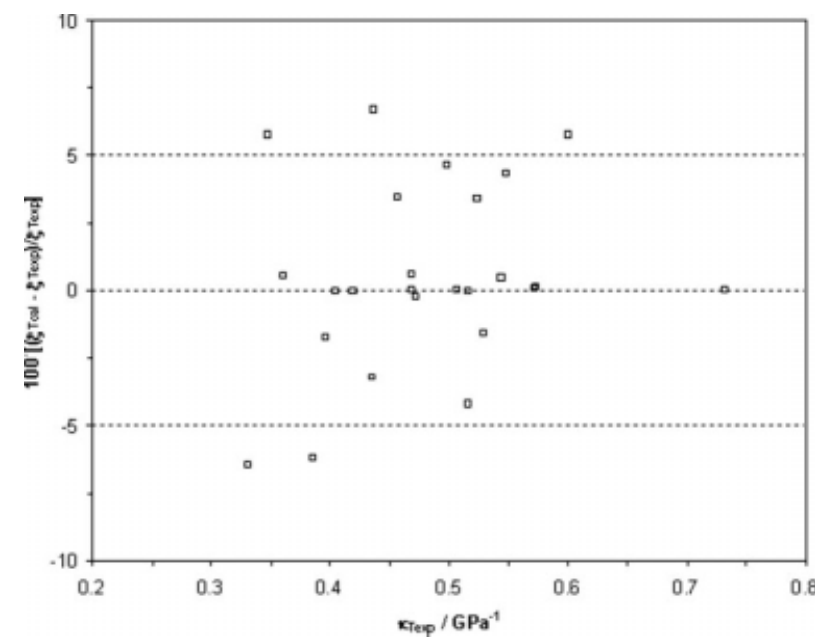

Figure 8. Relative deviations between the calculated and experimental isothermal compressibility as a function of experimental isothermal compressibility for imidazolium-, pyridinium-, pyrrolidinium-, piperidinium-, and phosphonium ionic liquids in the current study. ferent authors as described on the report of the IUPAC task group for the development of standard systems for the measurement of thermodynamic properties of ionic liquids (http://www.iupac.org/web/ins/2002-005-1-100). Care is recommended when comparing or using physical properties of ILs as differences among the results of several authors may be important since the presence of small amounts of water or other impurities such as chloride seem to have a remarkable effect on most of the these properties.

The proposed methods can be useful for predicting the studied properties for design of processes or products involving ionic liquids as the procedure involved are rapid and facile. They can also be used for the development of CAMD methods for ionic liquids that could help identify a compound, or range of compounds to fir a set of requirements for a particular application.

The group contribution methods here proposed can, in the future, be extended to a larger range of ionic liquids as data for these become available.

\section{Acknowledgements}

This work was supported by Fundação para a Ciência e a Tecnologia (Project POCI/EQU/58152/2004). R. L. Gardas acknowledges the financial support from Fundação para a Ciência e a Tecnologia through, his post-doctoral fellowship (SFRH/BPD/23246/2005).

\section{Notation}

$\left[\mathrm{C}_{\mathrm{n}} \mathrm{mIm}\right]^{+}=n$-alkyl-3-methylimidazolium cation

$\left[\mathrm{C}_{\mathrm{n}} \mathrm{eIm}\right]^{+}=n$-alkyl-3-ethylimidazolium cation

$\left[\mathrm{C}_{\mathrm{n}} \mathrm{mPy}\right]^{+}=n$-alkyl-3-methylpyridinium cation

$\left[\mathrm{C}_{\mathrm{n}} \mathrm{mPyr}\right]^{+}=n$-alkyl-1-methylpyrrolidinium cation

$\left[\mathrm{C}_{\mathrm{n}} \mathrm{mPip}^{+}=n\right.$-alkyl-1-methylpiperidinium cation

[THTDPh $^{+}=$trihexyl(tetradecyl)phosphonium cation

$[\mathrm{Am}(\mathrm{n}) \mathrm{nnn}]^{+}=n, n, n, n$-tetraalkylammonium cation

\section{Subscripts}

exp $=$ experimental property

$\mathrm{cal}=$ calculated property

\section{Literature Cited}

1. Smiglak M, Metlen A, Rogers RD. The second evolution of ionic liquids: from solvents and separations to advanced materialsenergetic examples from the ionic liquid cookbook. Acc Chem Res. 2007;40:1182-1192.

2. Gani R, Nielsen B, Fredenslund A. Group contribution approach to computer-aided molecular design. AIChE J. 1991;37:13181332

3. Harper PM, Gani R, Kolar P, Ishikawa T. Computer-aided molecular design with combined molecular modeling and group contribution. Fluid Phase Equilib. 1999;158-160:337-347.

4. Gardas RL, Coutinho JAP. Extension of the Ye and Shreeve group contribution method for density estimation of ionic liquids in a wide range of temperatures and pressures. Fluid Phase Equilib. 2008;263:26-32.

5. Gardas RL, Coutinho JAP. Applying a QSPR correlation to the prediction of surface tensions of ionic liquids. Fluid Phase Equilib. 2008;265:57-65.

6. Gardas RL, Coutinho JAP. A group contribution method for viscosity estimation of ionic liquids. Fluid Phase Equilib. 2008;266: 195-201.

7. Gardas RL, Coutinho JAP. Estimation of speed of sound of ionic liquids using surface tensions and densities: a volume based approach. Fluid Phase Equilib. 2008;267:182-186.

8. Gardas RL, Coutinho JAP. A group contribution method for heat capacity estimation of ionic liquids. Ind Eng Chem Res. 2008;47: 5751-5757. 
9. Bonhote P, Dias AP, Papageorgiou N, Kalyanasundaram K, Gratzel M. Hydrophobic, highly conductive ambient-temperature molten salts. Inorg Chem. 1996;35:1168-1178.

10. McEwen AB, Ngo HL, LeCompte K, Goldman JL. Electrochemical properties of imidazolium salt electrolytes for electrochemical capacitor applications. J Electrochem Soc. 1999;146:16871695.

11. Seddon KR, Stark A, Torres MJ. Influence of chloride, water, and organic solvents on the physical properties of ionic liquids. Pure Appl Chem. 2000;72:2275-2287.

12. Huddleston JG, Visser AE, Reichert WM, Willauer HD, Broker GA, Rogers RD. Characterization and comparison of hydrophilic and hydrophobic room temperature ionic liquids incorporating the imidazolium cation. Green Chem. 2001;3:156-164.

13. Noda A, Hayamizu K, Watanabe M. Pulsed-gradient spin-echo $1 \mathrm{H}$ and 19F NMR ionic diffusion coefficient, viscosity, and ionic conductivity of non-chloroaluminate room-temperature ionic liquids. J Phys Chem B. 2001;105:4603-4610.

14. Branco LC, Rosa JN, Moura Ramos JJ, Afonso CAM. Preparation and characterization of new room temperature ionic liquids. Chem Eur J. 2002;8:3671-3677.

15. Nishida T, Tashiro Y, Yamamoto M. Physical and electrochemical properties of 1-alkyl-3-methylimidazolium tetrafluoroborate for electrolyte. J Fluorine Chem. 2003;120:135-141.

16. Okoturo OO, VanderNoot TJ. Temperature dependence of viscosity for room temperature ionic liquids. $J$ Electroanal Chem. 2004;568:167-181.

17. Tokuda H, Hayamizu K, Ishii K, Susan MABH, Watanabe M. Physicochemical properties and structures of room temperature ionic liquids. 1. Variation of anionic species. J Phys Chem B. 2004;108:16593-16600.

18. Crosthwaite JM, Muldoon MJ, Dixon JK, Anderson JL, Brennecke JF. Phase transition and decomposition temperatures, heat capacities and viscosities of pyridinium ionic liquids. $J$ Chem Thermodyn. 2005;37:559-568.

19. Harris KR, Woolf LA, Kanakubo M. Temperature and pressure dependence of the viscosity of the ionic liquid 1-butyl-3-methylimidazolium hexafluorophosphate. J Chem Eng Data. 2005;50: $1777-1782$

20. Morgan D, Ferguson L, Scovazzo P. Diffusivities of gases in roomtemperature ionic Liquids: data and correlations obtained using a lag-time technique. Ind Eng Chem Res. 2005;44:4815-4823.

21. Tokuda H, Hayamizu K, Ishii K, Susan MABH, Watanabe M. Physicochemical properties and structures of room temperature ionic liquids. 2. variation of alkyl chain length in imidazolium cation. J Phys Chem B. 2005;109:6103-6110.

22. Arce A, Rodil E, Soto A. Volumetric and viscosity study for the mixtures of 2-ethoxy-2-methylpropane, ethanol, and 1-ethyl-3methylimidazolium ethyl sulfate ionic liquid. J Chem Eng Data. 2006;51:1453-1457.

23. Gomez E, Gonzalez B, Calvar N, Tojo E, Dominguez A. Physical properties of pure 1-ethyl-3-methylimidazolium ethylsulfate and its binary mixtures with ethanol and water at several temperatures. J Chem Eng Data. 2006;51:2096-2102.

24. Gomez E, Gonzalez B, Dominguez A, Tojo E, Tojo J. Dynamic viscosities of a series of 1-alkyl-3-methylimidazolium chloride ionic liquids and their binary mixtures with water at several temperatures. J Chem Eng Data. 2006;51:696-701.

25. Harris KR, Kanakubo M, Woolf LA. Temperature and pressure dependence of the viscosity of the ionic liquids 1-methyl-3-octylimidazolium hexafluorophosphate and 1-methyl-3-octylimidazolium tetrafluoroborate. J Chem Eng Data. 2006;51:1161-1167.

26. Jacquemin J, Husson P, Padua AAH, Majer V. Density and viscosity of several pure and water-saturated ionic liquids. Green Chem. 2006;8:172-180.

27. Rodriguez H, Brennecke JF. Temperature and composition dependence of the density and viscosity of binary mixtures of water + ionic liquid. $J$ Chem Eng Data. 2006:51:2145-2155.

28. Tokuda H, Tsuzuki S, Susan MABH, Hayamizu K, Watanabe M. How ionic are room-temperature ionic liquids? An indicator of the physicochemical properties. J Phys Chem B. 2006;110:19593-19600.

29. Tomida D, Kumagai A, Qiao K, Yokoyama C. Viscosity of $[\mathrm{bmim}][\mathrm{PF} 6]$ and $[\mathrm{bmim}][\mathrm{BF} 4]$ at high pressure. Int $J$ Thermophys. 2006;27:39-47.
30. Arce A, Rodriguez H, Soto A. Use of a green and cheap ionic liquid to purify gasoline octane boosters. Green Chem. 2007;9:247253.

31. Deng MJ, Chen PY, Sun IW. Electrochemical study and electrodeposition of manganese in the hydrophobic butylmethylpyrrolidinium bis((trifluoromethyl)sulfonyl)imide room-temperature ionic liquid. Electrochim Acta. 2007;53:1931-1938.

32. Gonzalez EJ, Gonzalez B, Calvar N, Dominguez A. Physical properties of binary mixtures of the ionic liquid 1-ethyl-3-methylimidazolium ethyl sulfate with several alcohols at $T=(298.15$, 313.15, and 328.15) $\mathrm{K}$ and atmospheric pressure. J Chem Eng Data. 2007;52:1641-1648.

33. Harris KR, Kanakubo M, Woolf LA. Temperature and pressure dependence of the viscosity of the ionic liquids 1-hexyl-3-methylimidazolium hexafluorophosphate and 1-butyl-3-methylimidazolium BiS(trifluoromethylsulfonyl)imide. J Chem Eng Data. 2007; 52: $1080-1085$

34. Harris KR, Kanakubo M, Woolf LA. Temperature and pressure dependence of the viscosity of the ionic liquid 1-butyl-3methylimidazolium tetrafluoroborate: Viscosity and density relationships in ionic liquids. J Chem Eng Data. 2007;52:24252430.

35. Kandil ME, Marsh KN, Goodwin ARH. Measurement of the viscosity, density, and electrical conductivity of 1-hexyl-3-methylimidazolium bis(trifluorosulfonyl)imide at temperatures between (288 and 433$) \mathrm{K}$ and pressures below $50 \mathrm{MPa}$. J Chem Eng Data. 2007:52:2382-2387.

36. Pereiro AB, Legido JL, Rodriguez A. Physical properties of ionic liquids based on 1-alkyl-3-methylimidazolium cation and hexafluorophosphate as anion and temperature dependence. $J$ Chem Thermodyn. 2007;39:1168-1175.

37. Pereiro AB, Verdia P, Tojo E, Rodriguez A. Physical properties of 1-butyl-3-methylimidazolium methyl sulfate as a function of temperature. J Chem Eng Data. 2007;52:377-380.

38. Sanmamed YA, Gonzalez-Salgado D, Troncoso J, Cerdeirina CA, Romani L. Viscosity-induced errors in the density determination of room temperature ionic liquids using vibrating tube densitometry. Fluid Phase Equilib. 2007;252:96-102.

39. Tomida D, Kumagai A, Kenmochi S, Qiao K, Yokoyama C. Viscosity of 1-hexyl-3-methylimidazolium hexafluorophosphate and 1-octyl-3-methylimidazolium hexafluorophosphate at high pressure. J Chem Eng Data. 2007;52:577-579.

40. Widegren JA, Magee JW. Density, viscosity, speed of sound, and electrolytic conductivity for the ionic liquid 1-hexyl-3-methylimidazolium bis(trifluoromethylsulfonyl)imide and its mixtures with water. J Chem Eng Data. 2007;52:2331-2338.

41. Bou Malham I, Turmine M. Viscosities and refractive indices of binary mixtures of 1-butyl-3-methylimidazolium tetrafluoroborate and 1-butyl-2,3-dimethylimidazolium tetrafluoroborate with water at 298 K. J Chem Thermodyn. 2008;40:718-723.

42. Chen H, He Y, Zhu J, Alias H, Ding Y, Paul N, Christopher H, David R, Tan C. Rheological and heat transfer behaviour of the ionic liquid, [ $\left.\mathrm{C}_{4} \mathrm{mim}\right]\left[\mathrm{NTf}_{2}\right]$. Int J Heat Fluid Flow. 2008;29:149-155.

43. Valkenburg MEV, Vaughn RL, Williams M, Wilkes JS. Thermochemistry of ionic liquid heat-transfer fluids. Thermochim Acta. 2005;425:181-188

44. Tomida D, Kenmochi S, Tsukada T, Qiao K, Yokoyama C. Thermal conductivities of $[\mathrm{bmim}]\left[\mathrm{PF}_{6}\right],[\mathrm{hmim}]\left[\mathrm{PF}_{6}\right]$, and $[\mathrm{omim}]\left[\mathrm{PF}_{6}\right]$ from 294 to $335 \mathrm{~K}$ at pressures up to $20 \mathrm{MPa}$. Int J Thermophys. 2007;28:1147-1160.

45. Ge R, Hardacre C, Nancarrow P, Rooney DW. Thermal conductivities of ionic liquids over the temperature range from $293 \mathrm{~K}$ to 353 K. J Chem Eng Data. 2007;52:1819-1823.

46. Widegren JA, Saurer EM, Marsh KN, Magee JW. Electrolytic conductivity of four imidazolium-based room-temperature ionic liquids and the effect of a water impurity. J Chem Thermodyn. 2005;37:569-575.

47. Kanakubo M, Harris KR, Tsuchihashi N, Ibuki K, Ueno M. Effect of pressure on transport properties of the ionic liquid 1-butyl-3methylimidazolium hexafluorophosphate. $J$ Phy Chem B. 2007;111:2062-2069.

48. Vila J, Gines P, Pico JM, Varela LM, Cabeza O. Temperature dependence of the electrical conductivity in EMIM-based ionic liquids: Evidence of Vogel-Tamman-Fulcher behavior. Fluid Phase Equilib. 2006;242:141-146. 
49. Bendova M, Wagner Z. Liquid-liquid equilibrium in binary system $[$ bmim $]\left[\mathrm{PF}_{6}\right]+$ 1-butanol. J Chem Eng Data. 2006;51:21262131.

50. Pereiro AB, Rodriguez A. Experimental liquid-liquid equilibria of 1-alkyl-3-methylimidazolium hexafluorophosphate with 1-alcohols. J Chem Eng Data. 2007;52:1408-1412.

51. Pereiro AB, Rodriguez A. Study on the phase behaviour and thermodynamic properties of ionic liquids containing imidazolium cation with ethanol at several temperatures. J Chem Thermodyn. 2007;39:978-989.

52. Pereiro AB, Rodríguez A. Ternary (liquid + liquid) equilibria of the azeotrope (ethyl acetate + 2-propanol) with different ionic liquids at $T=298.15 \mathrm{~K}$. J Chem Thermodyn. 2007;39:1608-1613.

53. Pereiro AB, Rodriguez A. Ternary liquid-liquid equilibria ethanol + 2-butanone + 1-butyl-3-methylimidazolium hexafluorophosphate, 2-propanol + 2-butanone + 1-butyl-3-methylimidazolium hexafluorophosphate, and 2-butanone + 2-propanol + 1,3-dimethylimidazolium methyl sulfate at 298.15 K. J Chem Eng Data. 2007;52:2138-2142.

54. Pereiro AB, Rodriguez A. Thermodynamic properties of ionic liquids in organic solvents from (293.15 to 303.15) K. J Chem Eng Data. 2007;52:600-608.

55. Zafarani-Moattar MT, Majdan-Cegincara R. Viscosity, density, speed of sound, and refractive index of binary mixtures of organic solvent + ionic liquid, 1-butyl-3-methylimidazolium hexafluorophosphate at 298.15 K. J Chem Eng Data. 2007;52:2359-2364.

56. Kumar A. Estimates of internal pressure and molar refraction of imidazolium based ionic liquids as a function of temperature. J Solut Chem. 2008;37:203-214.

57. Kumar A, Singh T, Gardas RL, Coutinho JAP. Non-ideal behaviour of a room temperature ionic liquid in an alkoxyethanol or poly ethers at $T=(298.15$ to 318.15$)$ K. J Chem Thermodyn. 2008;40:32-39.

58. Pereiro AB, Tojo E, Rodriguez A, Canosa J, Tojo J. Properties of ionic liquid HMIMPF6 with carbonates, ketones and alkyl acetates. J Chem Thermodyn. 2006;38:651-661.

59. Kim K-S, Shin B-K, Lee H, Ziegler F. Refractive index and heat capacity of 1-butyl-3-methylimidazolium bromide and 1-butyl-3methylimidazolium tetrafluoroborate, and vapor pressure of binary systems for 1-butyl-3-methylimidazolium bromide + trifluoroethanol and 1-butyl-3-methylimidazolium tetrafluoroborate + trifluoroethanol. Fluid Phase Equilib. 2004;218:215-220.

60. Iglesias-Otero MA, Troncoso J, Carballo E, Romani L. Density and refractive index for binary systems of the ionic liquid [Bmim][BF4] with methanol, 1,3-dichloropropane, and dimethyl carbonate. J Solut Chem. 2007;36:1219-1230.

61. Iglesias-Otero MA, Troncoso J, Carballo E, Romaní L. Density and refractive index in mixtures of ionic liquids and organic solvents: correlations and predictions. J Chem Thermodyn. 2008; 40:949-956.

62. Wagner M, Stanga O, Schroer W. The liquid-liquid coexistence of binary mixtures of the room temperature ionic liquid 1-methyl-3hexylimidazolium tetrafluoroborate with alcohols. Phys Chem Chem Phys. 2004;6:4421-4431.

63. Arce A, Rodríguez H, Soto A. Effect of anion fluorination in 1ethyl-3-methylimidazolium as solvent for the liquid extraction of ethanol from ethyl tert-butyl ether. Fluid Phase Equilib. 2006; 242:164-168.

64. Alonso L, Arce A, Francisco M, Rodriguez O, Soto A. Liquid-liquid equilibria for systems composed by 1-methyl-3-octylimidazolium tetrafluoroborate ionic liquid, thiophene, and $n$-hexane or cyclohexane. J Chem Eng Data. 2007;52:1729-1732.

65. Alonso L, Arce A, Francisco M, Soto A. Measurement and correlation of liquid-liquid equilibria of two imidazolium ionic liquids with thiophene and methylcyclohexane. J Chem Eng Data. 2007; 52:2409-2412.

66. Singh T, Kumar A. Physical and excess properties of a room temperature ionic liquid (1-methyl-3-octylimidazolium tetrafluoroborate) with n-alkoxyethanols (C1Em, $m=1$ to 3$)$ at $T=(298.15$ to 318.15) K. J Chem Thermodyn. 2008;40:417-423.

67. Arce A, Rodil E, Soto A. Physical and excess properties for binary mixtures of 1-methyl-3- octylimidazolium tetrafluoroborate, [Omim] $\left[\mathrm{BF}_{4}\right]$, ionic liquid with different alcohols. J Solut Chem. 2006;35:63-78.
68. Mokhtarani B, Mojtahedi MM, Mortaheb HR, Mafi M, Yazdani F, Sadeghian F. Densities, refractive indices, and viscosities of the ionic liquids 1-methyl-3-octylimidazolium tetrafluoroborate and 1-methyl3-butylimidazolium perchlorate and their binary mixtures with ethanol at several temperatures. J Chem Eng Data. 2008;53: 677-682.

69. Berthod A, Ruiz-Ángel MJ, Carda-Broch S. Ionic liquids in separation techniques. J Chromatogr A. 2008;1184:6-18.

70. Pereiro AB, Santamarta F, Tojo E, Rodriguez A, Tojo J. Temperature dependence of physical properties of ionic liquid 1,3-dimethylimidazolium methyl sulfate. J Chem Eng Data. 2006;51:952-954.

71. David W, Letcher TM, Ramjugernath D, Raal JD. Activity coefficients of hydrocarbon solutes at infinite dilution in the ionic liquid, 1-methyl-3-octyl-imidazolium chloride from gas-liquid chromatography. J Chem Thermodyn. 2003;35:1335-1341.

72. Arce A, Rodriguez O, Soto A. Experimental determination of liquid-liquid equilibrium using ionic liquids: tert-amyl ethyl ether + ethanol + 1-octyl-3-methylimidazolium chloride system at 298.15 K. J Chem Eng Data. 2004;49:514-517.

73. Gonzalez EJ, Alonso L, Dominguez A. Physical properties of binary mixtures of the ionic liquid 1-methyl-3-octylimidazolium chloride with methanol, ethanol, and 1-propanol at $T=(298.15$, 313.15, and 328.15) $\mathrm{K}$ and at $P=0.1 \mathrm{MPa}$. J Chem Eng Data. 2006;51:1446-1452.

74. Calvar N, Gomez E, Gonzalez B, Dominguez A. Experimental determination, correlation, and prediction of physical properties of the ternary mixtures ethanol + water with 1-octyl-3-methylimidazolium chloride and 1-ethyl-3-methylimidazolium ethylsulfate. J Chem Eng Data. 2007;52:2529-2535.

75. GomesdeAzevedo R, Esperanca JMSS, Najdanovic-Visak V, Visak ZP, Guedes HJR, Nunes da Ponte M, Rebelo LPN. Thermophysical and thermodynamic properties of 1-butyl-3-methylimidazolium tetrafluoroborate and 1-butyl-3-methylimidazolium hexafluorophosphate over an extended pressure range. J Chem Eng Data. 2005;50:997-1008.

76. Kabo GJ, Blokhin AV, Paulechka YU, Kabo AG, Shymanovich MP, Magee JW. Thermodynamic properties of 1-butyl-3-methylimidazolium hexafluorophosphate in the condensed state. $J$ Chem Eng Data. 2004;49:453-461.

77. Jacquemin J, Husson P, Mayer V, Cibulka I. High-pressure volumetric properties of imidazolium-based ionic liquids: effect of the anion. J Chem Eng Data. 2007;52:2204-2211.

78. Jacquemin J, Husson P, Majer V, Gomes MFC. Low-pressure solubilities and thermodynamics of solvation of eight gases in 1butyl-3-methylimidazolium hexafluorophosphate. Fluid Phase Equilib. 2006;240:87-95.

79. Kumean J, Kamps APS, Tuma D, Maurer G. Solubility of CO in the ionic liquid [bmim][PF6]. Fluid Phase Equilib. 2005;228229:207-211.

80. Troncoso J, Cerdeirina CA, Sanmamed YA, Romani L, Rebelo LPN. Thermodynamic properties of imidazolium-based ionic liquids: densities, heat capacities, and enthalpies of fusion of $[\mathrm{bmim}]\left[\mathrm{PF}_{6}\right]$ and $[\mathrm{bmim}]\left[\mathrm{NTf}_{2}\right]$. J Chem Eng Data. 2006;51: 1856-1859.

81. Gardas RL, Freire MG, Carvalho PJ, Marrucho IM, Fonseca IMA, Ferreira AGM, Coutinho JAP. High-pressure densities and derived thermodynamic properties of imidazolium-based ionic liquids. J Chem Eng Data. 2007;52:80-88.

82. Zhang S, Li X, Chen H, Wang J, Zhang J, Zhang M. Determination of physical properties for the binary system of 1-ethyl-3methylimidazolium tetrafluoroborate $+\mathrm{H}_{2} \mathrm{O}$. J Chem Eng Data. 2004;49:760-764.

83. Shiflett MB, Yokozeki A. Liquid-liquid equilibria in binary mixtures of 1,3-propanediol + ionic liquids [bmim] $\left[\mathrm{PF}_{6}\right]$, [bmim] $\left[\mathrm{BF}_{4}\right]$, and $[\mathrm{emim}]\left[\mathrm{BF}_{4}\right]$. J Chem Eng Data. 2007;52: 1302-1306.

84. Navia P, Trancoso J, Romani L. Excess magnitudes for ionic liquid binary mixtures with a common ion. J Chem Eng Data. 2007;52:1369-1374.

85. Zafarani-Moattar MT, Shekaari H. Application of Prigogine-FloryPatterson theory to excess molar volume and speed of sound of 1n-butyl-3-methylimidazolium hexafluorophosphate or 1-n-butyl-3methylimidazolium tetrafluoroborate in methanol and acetonitrile. J Chem Thermodyn. 2006;38:1377-1384.

86. Rebelo LPN, Najdanovic-Visak V, Visak ZP, Nunes da Ponte M, Szydlowski J, Cerdeirina CA, Troncoso J, Romani L, Esperança 
JMSS, Guedes HJR, de Sousa HC. A detailed thermodynamic analysis of $\left[\mathrm{C}_{4} \mathrm{mim}\right]\left[\mathrm{BF}_{4}\right]+$ water as a case study to model ionic liquid aqueous solutions. Green Chem. 2004;6:369-381.

87. Huo Y, Xia S, Ma P. Densities of ionic liquids, 1-butyl-3-methylimidazolium hexafluorophosphate and 1-butyl-3-methylimidazolium tetrafluoroborate, with benzene, acetonitrile, and 1-propanol at $T=$ (293.15 to 343.15) K. J Chem Eng Data. 2007;52:2077-2082.

88. Krummen M, Wasserscheid P, Gmehling J. Measurement of activity coefficients at infinite dilution in ionic liquids using the dilutor technique. J Chem Eng Data. 2002;47:1411-1417.

89. Jacquemin J, Husson P, Majer V, Costa Gomes MF. Influence of the cation on the solubility of $\mathrm{CO}_{2}$ and $\mathrm{H}_{2}$ in ionic liquids based on the bis(trifluoromethylsulfonyl)imide anion. J Solut Chem. 2007;36:967-979.

90. Gomes De Azevedo R, Esperanca JMSS, Szydlowski J, Visak ZP, Pires PF, Guedes HJR, Rebelo LPN. Thermophysical and thermodynamic properties of ionic liquids over an extended pressure range: $[\mathrm{bmim}]\left[\mathrm{NTf}_{2}\right]$ and $[\mathrm{hmim}]\left[\mathrm{NTf}_{2}\right] . J$ Chem Thermodyn. 2005:37:888-899.

91. Kumelan J, Perez-Salado Kamps A, Tuma D, Maurer G. Solubility of $\mathrm{CO} 2$ in the ionic liquid $[\mathrm{hmim}]\left[\mathrm{Tf}_{2} \mathrm{~N}\right]$. J Chem Thermodyn. 2006;38:1396-1401.

92. Kato R, Gmehling J. Systems with ionic liquids: Measurement of VLE and $\gamma^{\infty}$ data and prediction of their thermodynamic behavior using original UNIFAC, mod. UNIFAC(Do) and COSMO-RS(Ol). J Chem Thermodyn. 2005;37:603-619.

93. Vercher E, Orchilles AV, Miguel PJ, Martihez-Andreu A. Volumetric and ultrasonic studies of 1-ethyl-3-methylimidazolium trifluoromethanesulfonate ionic liquid with methanol, ethanol, 1-propanol, and water at several temperatures. J Chem Eng Data. 2007;52:1468-1482.

94. Gardas RL, Freire MG, Carvalho PJ, Marrucho IM, Fonseca IMA, Ferreira AGM, Coutinho JAP. P $\rho$ T measurements of imidazoliumbased ionic liquids. J Chem Eng Data. 2007;52:1881-1888.

95. Kato R, Gmehling J. Activity coefficients at infinite dilution of various solutes in the ionic liquids MMIM methylsulfate, MMIM methoxyethylsulfate, MMIM dimethylphosphate, $\mathrm{N}$ ethylpyridinium bis(trifluoromethylsulfonyl) imide and pyridiniumethoxyethylsulfate (MMIM=1-methyl-3-methylimidazolium). Fluid Phase Equilib. 2004;226:37-44.

96. Kumelan J, Perez-SaladoKamps D, Tuma D, Maurer G. Solubility of $\mathrm{CO}_{2}$ in the ionic liquids $[\mathrm{bmim}]\left[\mathrm{CH}_{3} \mathrm{SO}_{4}\right]$ and $[\mathrm{bmim}]\left[\mathrm{PF}_{6}\right]$. J Chem Eng Data. 2006;51:1802-1807.

97. Yang JZ, Lu XM, Gui JS, Xu WG, Li HW. Volumetric properties of room temperature ionic liquid. 2. The concentrated aqueous solutions of \{1-methyl-3-ethylimidazolium ethyl sulfate + water $\}$ in a temperature range of $278.2 \mathrm{~K}$ to $338.2 \mathrm{~K}$. J Chem Thermodyn. 2005;37:1250-1255.

98. Tong J, Zhang QG, Hong M, Yang JZ. Thermodynamic properties of ionic liquid BMIAlCl4. Acta Phys Chim Sin. 2006;22: 71-75.

99. Zhang QG, Yang JZ, Lu XM, Gui JS, Huang M. Studies on an ionic liquid based on $\mathrm{FeCl} 3$ and its properties. Fluid Phase Equilib. 2004:226:207-211.

100. Zhang QG, Wei Y. Study on properties of ionic liquid based on $\mathrm{ZnCl} 2$ with 1-butyl-3-methylimidazolium chloride. J Chem Thermodyn. 2008;40:640-644.

101. Yang JZ, Zhang QG, Xue F. Studies on the properties of EMIGaCl4. J Mol Liq. 2006;128:81-84.

102. Xu WG, Lu XM, Zhang QG, Gui JS, Yang JZ. Studies on the thermodynamic properties of the ionic liquid $\mathrm{BMIGaCl}_{4}$. Chin J Chem. 2006;24:331-335.

103. Zang SL, Zhang QG, Huang M, Wang B, Yang JZ. Studies on the properties of ionic liquid EMIInCl4. Fluid Phase Equilib. 2005;230:192-196

104. Yang JZ, Zhang QG, Huang M, Xue F, Zang SL. Properties of ionic liquid BMIInCl4 of rare metal at room temperature. Chem $J$ Chin Univ. 2005;26:1873-1876.

105. Gardas RL, Costa HF, Freire MG, Carvalho PJ, Marrucho IM, Fonseca IMA, Ferreira AGM, Coutinho JAP. Densities and derived thermodynamic properties of imidazolium-, pyridinium-, pyrrolidinium-, and piperidinium-based ionic liquids. J Chem Eng Data. 2008;53:805-811.

106. Gu Z, Brennecke JF. Volume expansivities and isothermal compressibilities of imidazolium and pyridinium-based ionic liquids. J Chem Eng Data. 2002;47:339-345.

107. Bandres I, Giner B, Artigas H, Royo FM, Lafuente C. Thermophysic comparative study of two isomeric pyridinium-based ionic liquids. J Phys Chem B. 2008;112:3077-3084.

108. Heintz A, Klasen D, Lehmann JK. Excess molar volumes and viscosities of binary mixtures of methanol and the ionic liquid 4methyl- $N$-butylpyridinium tetrafluoroborate at 25,40 , and $50^{\circ} \mathrm{C}$. J Solut Chem. 2002;31:467-476.

109. Anthony JL, Anderson JL, Maginn EJ, Brennecke JF. Anion effects on gas solubility in ionic liquids. J Phys Chem B. 2005; 109:6366-6374.

110. Esperanca JMSS, Guedes HJR, Blesic M, Rebelo LPN. Densities and derived thermodynamic properties of ionic liquids. 3. Phosphonium-based ionic liquids over an extended pressure range. J Chem Eng Data. 2006;51:237-242.

111. Kilaru P, Baker GA, Scovazzo P. Density and surface tension measurements of imidazolium-, quaternary phosphonium-, and ammonium-based room-temperature ionic liquids: data and correlations. J Chem Eng Data. 2007;52:2306-2314.

112. NIST Ionic Liquids Database, ILThermo. NIST Standard Reference Database 147. National Institute of Standards and Technology, Standard Reference Data Program, Gaithersburg, MD, 2006. Available at: http://ILThermo.boulder.nist.gov/ILThermo/.

113. Poling BE, Prausnitz JM, O'Connell JP. The Properties of Gases and Liquids. 5th ed. New York: McGraw-Hill, 2000.

114. Walden P. Organic solutions- and ionisation means. III. Chapter: internal friction and its connection with conductivity. Z Phys Chem. 1906;55:207-249.

115. Bockris JOM, Hooper GW. Self-diffusion in molten alkali halides. Discuss Faraday Soc. 1961;32:218-236.

116. Jarosik A, Krajewski SR, Lewandowski A, Radzimski P. Conductivity of ionic liquids in mixtures. $J$ Mol Liq. 2006;123:43-50.

117. Angell CA, Xu W, Yoshizawa M, Hayashi A, Belieres JP. Transport-vapor pressure relations, and fragility in ionic liquids: The Front and Future of Material Development. Tokyo: CMC, 2003.

118. Bagno A, D'Amico F, Saielli G. Computer simulation of diffusion coefficients of the room-temperature ionic liquid $[\mathrm{bmim}]\left[\mathrm{BF}_{4}\right]$ : Problems with classical simulation techniques. J Mol Liq. 2007; 131-132:17-23.

119. Shah RK, Sekulic DP. Fundamentals of Heat Exchanger Design. New York: Wiley. 2003.

120. Liu W, Cheng L, Zhang Y, Wang H, Yu M. The physical properties of aqueous solution of room-temperature ionic liquids based on imidazolium: Database and evaluation. $J$ Mol Liq. 2008;140:68-72.

121. Zhang M, Reddy RG. Application of $\left[\mathrm{C}_{4} \mathrm{mim}\right]\left[\mathrm{Tf}_{2} \mathrm{~N}\right]$ ionic liquid as thermal storage and heat transfer fluids. ECS Trans. 2007;2(28):27-34.

122. Rodriguez H, Williams M, Wilkes JS, Rogers RD. Ionic liquids for liquid-in-glass thermometers. Green Chem. 2008;10: 501-507.

123. Predel T, Schlucker E, Wasserscheid P, Gerhard D, Arlt W. Ionic liquids as operating fluids in high pressure applications. Chem Eng Tech. 2007;30:1475-1480.

124. Esperanca JMSS, Visak ZP, Plechkova NV, Seddon KR, Guedes HJR, Rebelo LPN. Density, speed of sound, and derived thermodynamic properties of ionic liquids over an extended pressure range. 4. $\left[\mathrm{C}_{3} \mathrm{mim}\right]\left[\mathrm{NTf}_{2}\right]$ and $\left[\mathrm{C}_{5} \mathrm{mim}\right]\left[\mathrm{NTf}_{2}\right]$. J Chem Eng Data. 2006;51:2009-2015.

125. Tariq M, Costa Gomes MF, Canongia Lopes JN, Rebelo LPN. Densities and Refractive Indices of Imidazolium and Phosphonium based Ionic Lequids: Effect of Temperature, Alkyl Chain Length and Anion. J Chem Thermodyn. 2008;41(6):790-798.

Manuscript received Apr. 21, 2008, and revision received Sept. 19, 2008. 